\title{
Deterioration of the FRP-to-concrete interface subject to moisture ingress: effects of conditioning methods and silane treatment
}

\author{
Shahrooz Amidi, Jialai Wang ${ }^{1}$ \\ Department of Civil, Construction, and Environmental Engineering, The University of \\ Alabama, Tuscaloosa, AL 35487, USA
}

\begin{abstract}
Fiber reinforced plastics (FRP) composites have emerged as one popular material in retrofit/rehabilitation of concrete structural members in last decades. The long-term durability of the FRP-to-concrete interface in aggressive environments plays a critical role in the success of this technique. An experimental program has been carried out in this study to examine the effect of moisture on the deterioration of the FRP-to-concrete interface. In addition to condition the specimens through fully submerging the specimens in water, a new method to condition the specimen through submerging only the bottom half of the specimen in water was used in this study. Testing results suggest that the fracture toughness of the FRP-to-concrete interface conditioned through half immersion is significantly higher than that of the interface conditioned through full immersion. Three possible responsible mechanisms have been identified: different moisture distributions along the epoxy-concrete interface induced by conditioning methods; faster moisture diffusion through the epoxy-concrete interface, and hygroscopic swelling stress induced by the swelling of the epoxy after absorbing moisture. The significant effect of the conditioning method on the durability of the FRP-to-concrete interface makes us postulate that the laboratory testing method based on full immersion of the specimen in water could exaggerate the deterioration of the interface induced by the moisture in real applications, in which the

\footnotetext{
${ }^{1}$ Corresponding author. Tel.: +1 205348 6786; fax: +1 2053480783.

Email address: jwang@eng.ua.edu (J.Wang)
} 
interface is exposed to air, rather than water. In such a case, neither the moisture diffusion along the epoxy-concrete interface nor the swelling of the interface is as significant as in the case of full immersion in water used in the laboratory testing. In addition, this study also evaluated the potential of silane coupling agent on enhancing the durability of the FRP-to-concrete interface in moisture conditions.

Keywords: Fiber reinforced polymers; epoxy; concrete; coupling agent; interface debonding; moisture diffusion; fracture toughness.

\section{Introduction}

For many years fiber reinforced polymer (FRP) composites have been considered as one of the most promising materials for construction [1-7]. One popular application of these materials is retrofitting/rehabilitation reinforced concrete structures through external bonding. This technique has the minimal impact on the surrounding environment and is far easier and faster to be implemented compared to other enhancement techniques. Extensive studies have been conducted on the durability of FRP strengthened reinforced concrete structures [8-15]. These study suggest that the durability of the FRP-to-concrete interface plays a critical role in the durability of the FRP strengthened structures [8].

The durability of the FRP-to-concrete interface in aggressive environments is mainly examined through experimental studies [12-15,17-28]. Two important conclusions can be draw from these studies. First, substantial loss of the fracture toughness of the interface can be induced by moisture. Second, the debonding locus shifts from within the concrete cover in its dry state to along the adhesive-concrete interface in its wet state. In these experimental studies, testing 
specimens were conditioned through fully immersing the specimens in water. Experimental observations and numerical simulation suggest that this conditioning method introduce nonuniform distribution of the relative humidity along the adhesive-concrete interface because water diffusion from outside boundaries into the interface is mainly determined by its path. This nonuniform distribution of the relative humidity makes it difficult to correlate the residual fracture toughness of the interface to the relative humidity at the interface $\left(I_{R H}\right)$. In current practice, this $I_{R H}$ is replaced by an apparent value which can be chosen as the average relative humidity across the interface [26]. The major problem of using the average value to represent the moisture status of the whole interface in the width direction is obvious; the difference in real relative humidity distribution is ignored. We can obtain the same average relative humidity across the epoxyconcrete interface by using different specimens and conditioning durations, while the real moisture distribution across the interface in these specimens could be significantly different. As a result, relationships between the residual strength of the epoxy-concrete interface and this apparent $I_{R H}$ don't reflect the intrinsic feature of the moisture-induced deterioration of the interface. In addition, these relationships are specimen-dependent, making it impossible to generalize the laboratory observations.

One objective of this study is to evaluate the effect of the non-uniform moisture distribution across the epoxy-concrete interface on the durability testing results. To this end, two different FRP-to-concrete interface specimens were manufactured and conditioned in different ways to introduce different moisture distributions across the epoxy-concrete interface. The induced deterioration of the interface was determined by measuring the fracture toughnesses of the interface under mode-I loading before and after conditioning. 
Another objective of this study is to evaluate the potential of using silane coupling agent to enhance the durability of the FRP-to-concrete interface in moisture condition. It is understood that the bond between dissimilar materials (polymers and minerals) cannot be water-resistant unless a third intermediate material called coupling agent applied within the interface. Organofunctional silane coupling agents are commonly used as mediator to bind organic materials to inorganic materials [29]. Ye et al. [30] applied a silane primer to enhance the strength of the FRP-to-concrete bonded interface. They found that applying silane primers improved the bonding strength of the FRP-to-concrete interface with poorly treated concrete surfaces. When the adhesive is applied to well-treated concrete surfaces, however, the enhancing effect of the silane coupling agent on the bond strength diminishes. This is because the bond strength between the adhesive and well-treated concrete surface is higher than the neighboring concrete. As a result, the measured strength of the FRP-to-concrete interface is actually the strength of the substrate concrete, not the interface [30]. Once silane is used as primer to treat the surface of concrete substrate, there are two possible mechanisms which will enhance the durability of the FRP-to-concrete interface significantly. 1) Covalent chemical bonds Si-O-Si between the concrete (of which the major component is silicate bond $\mathrm{Si}-\mathrm{O}-\mathrm{Si}$ ) and epoxy can be formed; which are much stronger than the hydrogen bonds between epoxy and concrete when only epoxy primer is used. 2) A hydrophobic organosilicate layer at the surface of concrete can be formed which can effectively reduce the ingress and subsequent hydrolysis.

\section{Experimental Program}

\subsection{Specimens}


Wedge driving test was adopted to measure the fracture toughness of the FRP-to-concrete interface under mode-I loading. The FRP-to-concrete interface specimen consists of a layer of CFRP pre-cured plate, a layer of epoxy adhesive and a concrete block, as shown in Fig.1. The same method used in our previous study was adopted to manufacture the specimen and treat the surface of the concrete blocks [15]. The bonding surfaces of the concrete blocks were sandblasted for about 5 minutes to provide rough surfaces for better bonding between the concrete and the epoxy. The produced bonding surface were cleaned by high pressured air, and then wiped with a wet cloth. The sandblasted CFRP sheets were cleaned with an acetone-soaked cloth to remove all contaminants. A pre-crack with a length about $3 \mathrm{~mm}(1 / 8 \mathrm{inch})$ is produced by applying a thick Teflon tape on the concrete block to assist crack initiation through the interface between the epoxy and the concrete. A steel wedge with thickness of $\Delta$ will be driven into the interface crack. As shown in Fig. 1, $a$ is the effective length between the wedge contact point and the crack tip. The concrete block of the specimen has a width of $50.8 \mathrm{~mm}$ which is equal to the width of the commercially available CFRP plate. To evaluate the effect of the specimen size and conditioning methods on the durability testing result, two different depths were used for the concrete blocks: $50.8 \mathrm{~mm}$ for the specimen conditioned through fully immersing in water (Fig. 1(a)), and $25.4 \mathrm{~mm}$ for the specimen conditioned through immersing half of the concrete block in water (Fig. 1(b)). For the specimen shown in Fig. 1(b), the upper half concrete block of the specimen is covered with a thick layer of a concrete sealer to prevent water ingress above the predefined 50\% submerging level of this test. The regions adjacent to the bond were grinded to eliminate possible bridge of sealer alongside the interface. Specimens shown in Fig. 1(a) were conditioned in a water tank through full immersion; while the specimen shown in Fig. 1(b) were conditioned through submerging only the bottom half of the concrete 
block of the specimens in water. The purpose of this design and half immersion conditioning is to avoid possible fast moisture diffusion through the epoxy-concrete interface, and to create more uniform moisture distribution along this interface. Since longer time is needed for a half immersed specimen to reach the same relative humidity level along the interface than a fully immersed one, the thickness of the half immersed specimen is reduced to the half of the fully immersed specimen to reduce the conditioning time.

To evaluate the potential of silane coupling agent on enhancing the durability of the FRP-toconcrete interface, a commercially available silane coupling agent based on $\gamma$ glycidoxypropyltrimethoxysilane ( $\gamma$-GPS) was used to treat the binding surfaces of the concrete blocks of the specimens. Ye et al. [30] showed that applying $1 \%$ aqueous solution of silane coupling agent on concrete surfaces can enhance the bonding strength between the adhesive and concrete. A study on of adhesively bonded aluminum alloy joints shows that treating the alloy by silane coupling agent with a concentration of $1 \%$ at $p H 5$ and hydrolyzed for $1 \mathrm{~h}$ prior to application can most effectively enhance the durability of the interface [31]. Therefore, $1 \%$ silane solution (aqueous) was prepared. After hydrolyzing for one hour in room temperature, the silane solution was continuously brushed onto the bonding surface of the concrete block for a period of 10 minutes. The treated concrete blocks were then immediately dried in a preheated oven at $93{ }^{\circ} \mathrm{C}$ for one hour. Then the dried blocks were removed from the oven and cooled down to ambient temperature in the laboratory. The treated concrete blocks were then used to manufacture the CFRP-to-concrete bonded interface specimens.

The concrete blocks were cast and cured for 28 days following ASTM C33/C33M [32] and ASTM C192/C192M [33], and then dried in a laboratory at room temperature $\left(23^{\circ} \mathrm{C}\right)$ for more than two weeks. The mean 28-day compressive strength of the block in 100 x $200 \mathrm{~mm}$ cylinders 
was measured as 44.5 MPa. Geometries and mechanical properties of CFRP plates and the Tyfo TC adhesive for binding between concrete and CFRP plate are shown in Table 1 and Table 2 respectively.

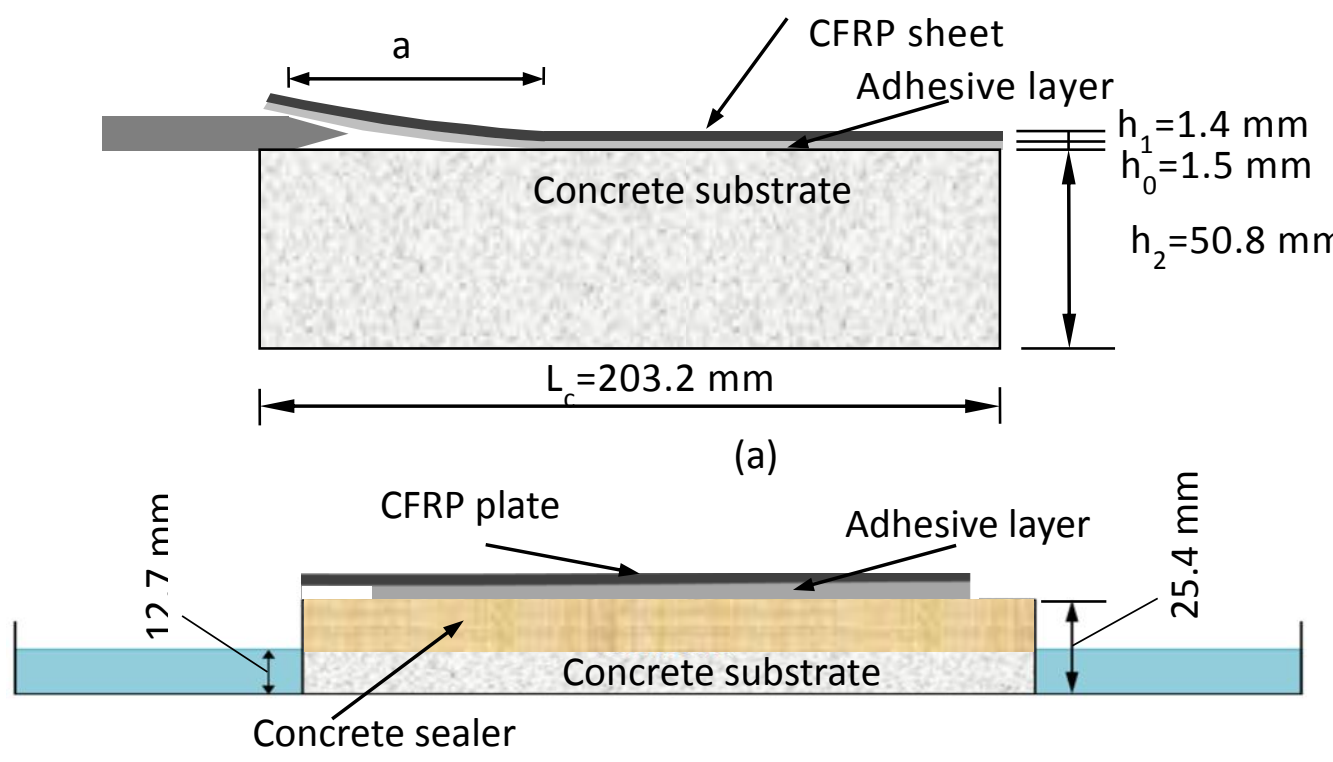

(b)

Fig. 1 Wedge driving test specimen: (a) specimen conditioned through full immersing; (b) specimen conditioned through half immersing.

Table 1 Mechanical properties of CFRP

\begin{tabular}{llllll}
\hline $\begin{array}{l}\text { Laminate } \\
\text { Width }\end{array}$ & $\begin{array}{l}\text { Laminate } \\
\text { Thickness }\end{array}$ & $\begin{array}{l}\text { Cross } \\
\text { Sectional } \\
\text { Area }\end{array}$ & $\begin{array}{l}\text { Tensile } \\
\text { Strength }\end{array}$ & $\begin{array}{l}\text { Tensile } \\
\text { Modulus of } \\
\text { Elasticity }\end{array}$ & $\begin{array}{l}\text { Ultimate } \\
\text { Strain }\end{array}$ \\
\hline $50.8 \mathrm{~mm}$ & $1.397 \mathrm{~mm}$ & $71.10 \mathrm{~mm} 2$ & $2413 \mathrm{MPa}$ & $131,000 \mathrm{MPa}$ & $0.0187 \%$ \\
\hline
\end{tabular}

Table 2 Mechanical properties of Epoxy

\begin{tabular}{llllllll}
\hline Compressive & $\begin{array}{l}\text { Epoxy } \\
\text { layer } \\
\text { Wtrength }\end{array}$ & $\begin{array}{l}\text { Epoxy } \\
\text { layer } \\
\text { Thicknes } \\
\mathrm{s}\end{array}$ & $\begin{array}{l}\text { Cross } \\
\text { Sectional } \\
\text { Area }\end{array}$ & $\begin{array}{l}\text { Tensile } \\
\text { Strength }\end{array}$ & $\begin{array}{l}\text { Tensile } \\
\text { Modulus }\end{array}$ & $\begin{array}{l}\text { Flexural } \\
\text { Modulus }\end{array}$ & $\begin{array}{l}\text { Flexural } \\
\text { Strength }\end{array}$ \\
\hline $28.2 \mathrm{MPa}$ & $50.8 \mathrm{~mm}$ & $1.50 \mathrm{~mm}$ & $\begin{array}{l}76.2 \\
\mathrm{~mm} 2\end{array}$ & $22.7 \mathrm{MPa}$ & $\begin{array}{l}1,200 \\
\mathrm{MPa}\end{array}$ & $\begin{array}{l}1.23 \\
\mathrm{GPa}\end{array}$ & $45.8 \mathrm{MPa}$ \\
\hline
\end{tabular}




\subsection{Experimental set-up}

The experimental set-up for wedge driving test is shown in Fig. 2, which consists of a homemade steel fixture, a digital camera, and a servo-controlled hydraulic loading frame (MTS810) to apply load. All specimens were conditioned as described before for different durations to simulate different levels of deterioration induced by water.

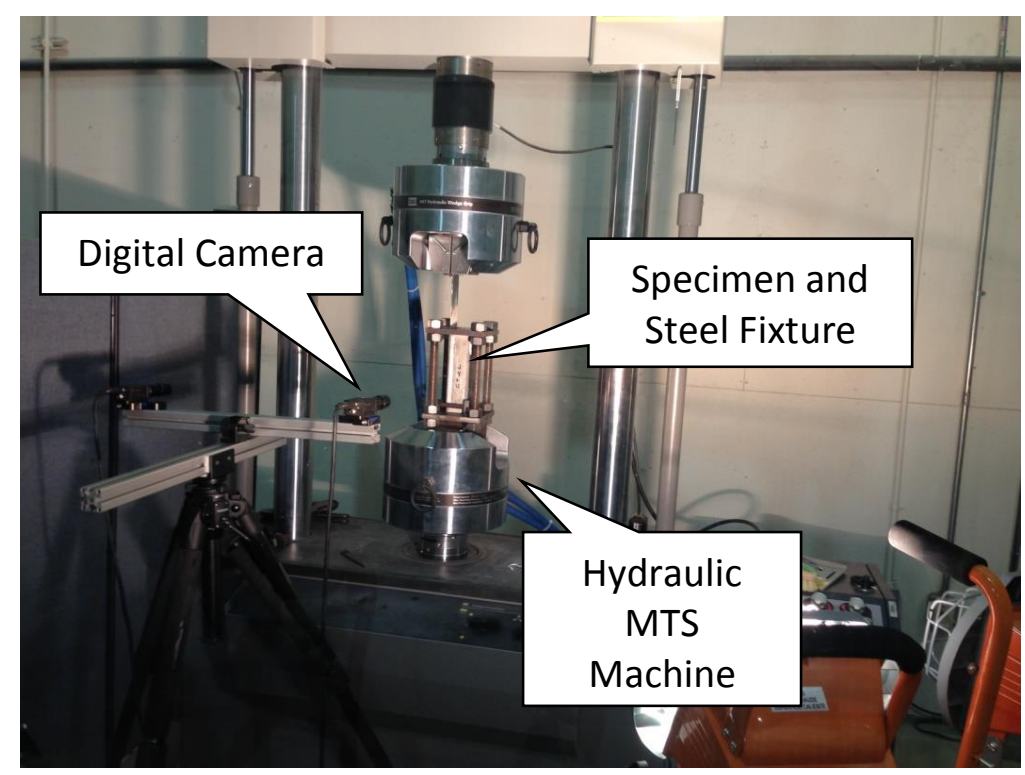

Fig. 2 Wedge driving test set-up for measuring Mode I fracture toughness of the CFRP-toconcrete interface

A $3.175 \mathrm{~mm}$ thick steel wedge fabricated according to ASTM D3762-03 (ASTM 2010) was driven into the pre-crack of the specimen at an intermediate speed of $2.54 \mathrm{~mm} /$ minute using the MTS machine. The high resolution digital camera was used to monitor the crack growth by taking images at the crack tip every one second, as shown in Fig.2. From the captured images, the length of the propagated crack $a$ was determined by the distance between the crack tip and the wedge contact point (Fig. 3). The mode-I energy release rate (ERR) at the crack tip can be calculated as [34] 
$G_{I}=\frac{9 D \Delta^{2}}{2 b a^{4}}$,

where, $b, D$, and $\Delta$ are width of the specimen, bending stiffness of the CFRP-adhesive composite beam, and the wedge thickness at the contact point, respectively.

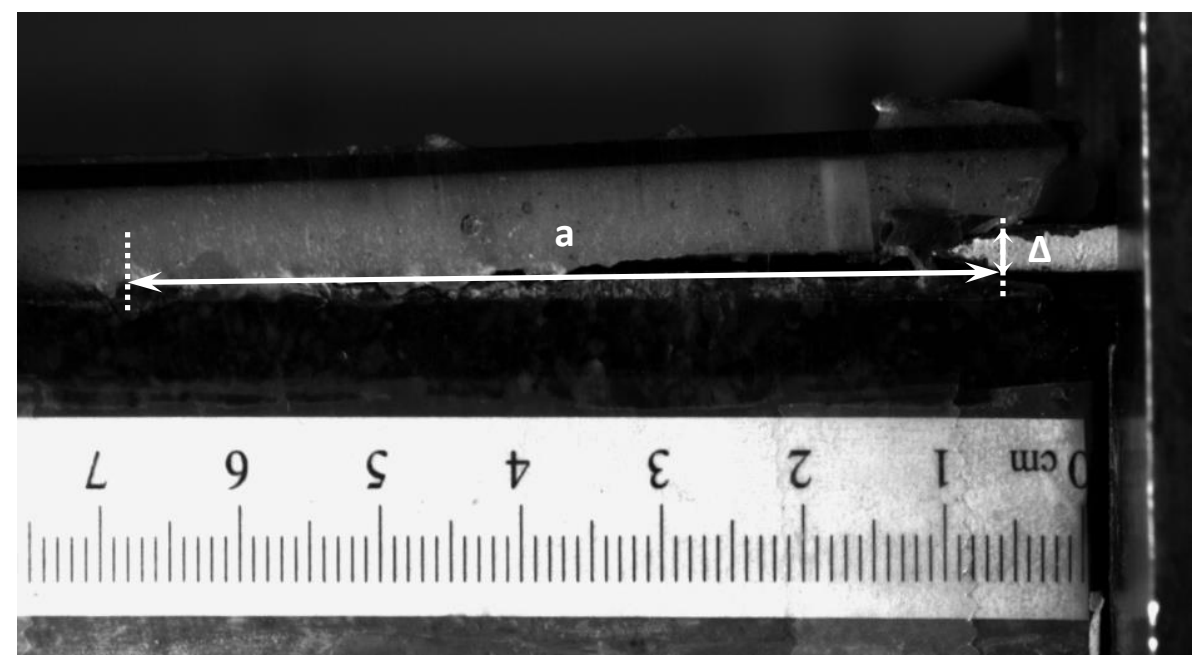

Fig. 3 .Typical image of a specimen under wedge driving

\section{3 Water absorption testing}

The water absorption tests were conducted using thin rectangular specimens cut from the same materials (CFRP, epoxy and concrete) used in the fracture toughness tests, as shown in Fig.4. Since the thickness of the samples is much smaller than their length and width, we can assume that water only diffuses perpendicularly to the mid-plane of the samples, instead of a three-dimension problem. To minimize water diffusion from four sides and ensure onedimensional flux through two large surfaces of these specimens, the sides of each sample were covered with a sealant. The moisture content of the specimen during the absorption testing can be expressed as [36] 


$$
M=G\left(M_{m}-M_{i}\right)+M_{i}
$$

where $M_{i}$ and $M_{m}$ are the initial moisture content and the maximum moisture content, respectively; $G$ is a dependent parameter and can be calculated as [36]

$$
G=\frac{M-M_{i}}{M_{m}-M_{i}}=\frac{8}{\pi^{2}} \sum_{j=0}^{\infty} \frac{\exp \left[-(2 j+1)^{2} \cdot \pi^{2}\left(D_{w}^{i} \cdot \frac{t}{s^{2}}\right)\right]}{(2 j+1)^{2}}
$$

Equation (3) can be simplified as [36]

$$
G=1-\exp \left[7.3\left(D_{w}^{i} \cdot \frac{t}{s^{2}}\right)^{0.75}\right]
$$

where $t$ is the time and $s$ is the thickness for the material exposed to the same environment on both sides. Moisture diffusivities will be obtained by fitting experimental data to the expression of Eq. (4).

Specimens used for absorption testing were first dried in an oven at $45^{\circ} \mathrm{C}$ until no change in the mass is observed. After registering the dry weight and assuming the initial moisture content $M_{i}=0$, all specimens were conditioned in a water tank at room temperature $\left(23^{\circ} \mathrm{C}\right)$. The mass of the specimens at different conditioning times were weighed using a digital lab scale after removing the surface moisture with a moistened cloth to obtain moisture content. After mass measurement, the specimens were returned to the tank for further conditioning. This procedure was repeated until no evident change of mass was reached. 


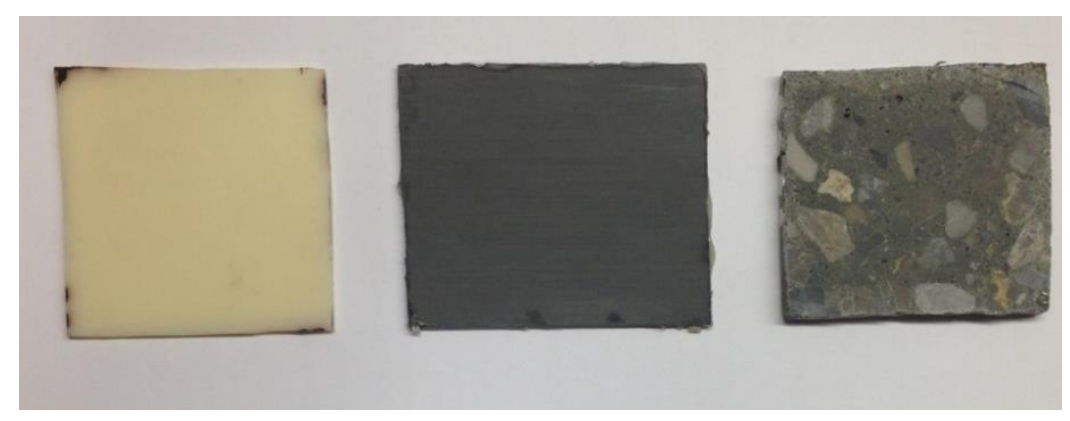

Fig. 4 Samples used in water absorption test: a) epoxy sample; b) CFRP sample; b) concrete sample.

\subsection{Testing plan}

Four groups of specimens (without silane treatment and conditioned through full immersion, with silane treatment and conditioned through full immersion, without silane treatment and conditioned through half immersion, with silane treatment and conditioned through half immersion) were manufactured, conditioned, and tested in this study. The fully-immersed specimens were conditioned for one, three and six months in water, and the half-immersed specimens were conditioned for $4,8,16$ weeks. A control group were manufactured without using silane treatment and stored in ambient environment of the laboratory. To examine the reversibility of the deterioration of the interface induced by moisture, some fully-immersed specimens were dried at room temperature $\left(23^{\circ} \mathrm{C}\right)$ for two days and then tested in the same way as the wet specimens, which were tested immediately after taken out of conditioning water. All testing data shown in this study are the average of three or four duplicated specimens. The arrangement of tested specimens is summarized in Tables 3 and 4. 
Table 3 Arrangement of fully immersed specimens

\begin{tabular}{llllll}
\hline $\begin{array}{l}\text { Time } \\
\text { (months) }\end{array}$ & \multicolumn{2}{l}{ Number of specimens } & & \\
\cline { 2 - 6 } & Control & Wet-untreated & Wet-silane & Dry- untreated & Dry-silane \\
\hline 1 & & 3 & 3 & 3 & 3 \\
3 & 4 & 3 & 3 & 3 & 3 \\
6 & & 3 & 3 & 3 & 3 \\
\hline
\end{tabular}

Table 4 Arrangement of half immersed specimens

\begin{tabular}{cccc}
\hline Time & \multicolumn{3}{c}{ Number of specimens } \\
\cline { 2 - 4 } (weeks) & Control & Wet- untreated & Wet-silane \\
\hline 4 & & 3 & 3 \\
8 & 4 & 3 & 3 \\
16 & & 3 & 3 \\
\hline
\end{tabular}

\section{Moisture diffusion simulation}

Water molecules can diffuse into the specimen through all the surfaces in contact with mater during conditioning. Figure 5 shows a cross-section of fully immersed FRP-to-concrete specimen to which water ingress can happen from all sides. The governing equation of moisture diffusion can be expressed considering by Fick's second law and Darcy's law [35]

$\frac{\partial H(x, z, t)}{\partial t}=\nabla\left(D_{w}^{i}(C(x, z, t) \times \nabla H(x, z, t))\right)$,

where $H(x, z, t)$ is the relative humidity $(\mathrm{RH})$ in the specimen, $D_{w}^{i}(i=1,2,3)$ are moisture diffusivity (diffusion coefficient) of the CFRP, the epoxy, and the concrete, respectively, and $t$ denotes the diffusion time. $x$ and $z$ are the axes of the coordinate system originated at the interface shown in Fig.5. Moisture continuity conditions along the CFRP-epoxy and epoxyconcrete interfaces require 
$\frac{\partial H(x, z, t)}{\partial z} \nabla\left(D_{w}^{i}(C(x, z, t))=\frac{\partial H(x, z, t)}{\partial z} \nabla\left(D_{w}^{i+1}(C(x, z, t))\right), \quad i=1,2,3\right.$.

It would be difficult to find a closed-form solution for the water diffusion using Eq. (5). Therefore, a finite element method employed by Ouyang and Wan [35] is used to simulate threedimension models of the FRP-to-concrete interface specimens using ABAQUS/CAE (Fig. 6). This is done through converting the moisture diffusion problem into a heat-flux problem which can be solved by the ABAQUS. 8-node linear brick for heat transfer (DC3D8) elements were used to mesh the specimen. A refined mesh with element size of $1 \mathrm{~mm}$ close to the bi-material interface was adopted for all three materials.

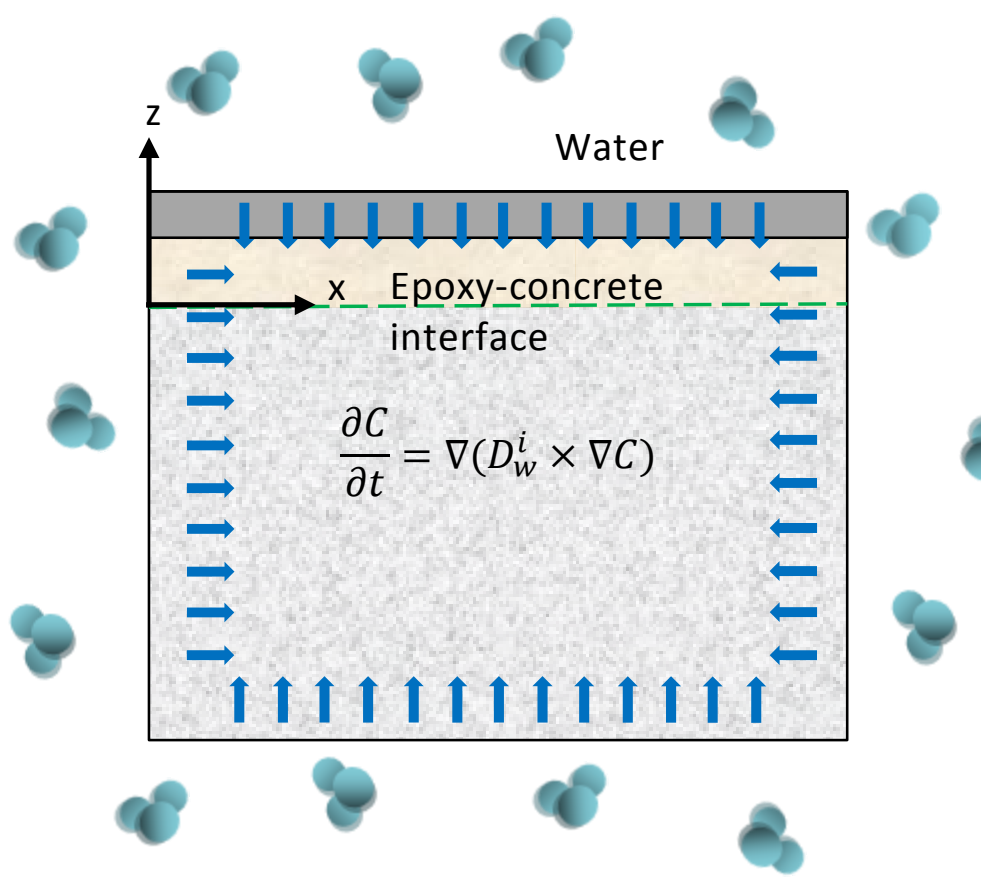

Fig. 5 Schematic illustration of the water diffusion towards the epoxy-concrete interface 


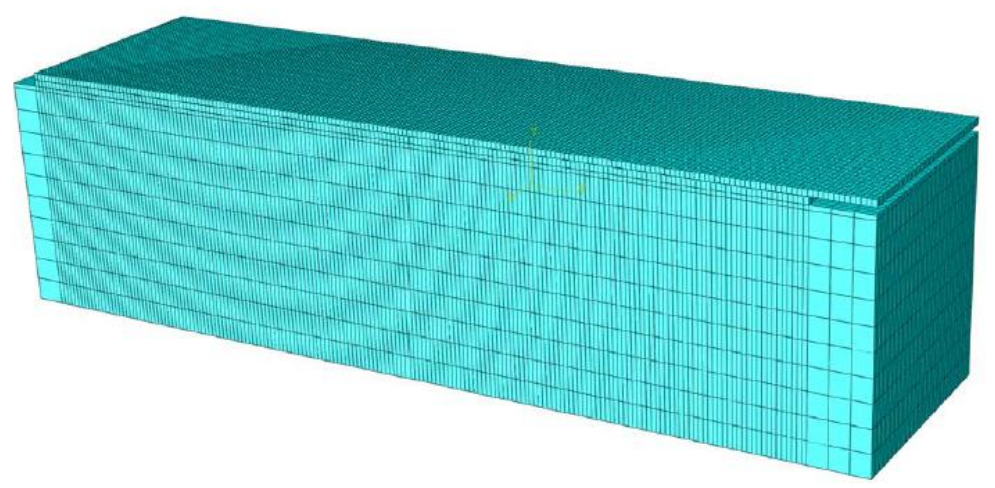

Fig. 6. FEA model for moisture diffusion in the FRP-to-concrete interface specimen

In this simulation, the boundary conditions for outer surfaces in contact with water were set as environmental $\mathrm{RH}=100 \%$. The concrete, CFRP and the epoxy were assumed initially dry with $\mathrm{RH}=0$. Diffusion coefficients of the concrete, CFRP, and the epoxy were measured through water absorption tests.

\section{Results and discussion}

\subsection{Degradation of the FRP-to-concrete interface induced by moisture ingress}

Experimental results of the fracture toughness of the FRP-to-concrete interface conditioned through immersing the whole specimen in water are shown in Table 5. Average of each group with the standard deviation is shown in Fig. 7. In this figure, "wet" refers to specimens tested immediately after being removed from the water tank, and "dry" refers to specimens tested after drying in the laboratory for two days. It can be seen that if the interface was not treated with silane, one-month fully immersing in water reduced the fracture toughness of the interface to only $35 \%$ of that of the control specimen. This fracture toughness was further reduced to $22 \%$ after three-month conditioning. After that, no significant reduction of the fracture toughness can be observed for extended water conditioning, indicating that degradation of the interface induced 
by water can be completed through three-month conditioning in water. The steady reading of the fracture toughness after sufficient conditioning is therefore referred to as residual fracture toughness of the interface. Similarly, significant reduction in the fracture toughness is observed for the specimens treated with silane. After conditioning in water for one month, the fracture toughness of the interface was reduced to $51 \%$ of that of the control specimen, as shown in Fig. 7. After three-month conditioning in water, no further reduction of the fracture toughness can be observed and the residual fracture toughness was measured as $28 \%$ of that of the control group (Fig. 7). This suggests that silane treatment does improve the residual fracture toughness of the FRP-to-concrete interface attacked by water, confirming that silane coupling agent can improve the durability of the interface subject to moisture attack.

If the specimens were dried in the laboratory for two days before testing, higher fracture toughness can be obtained for all specimens than those tested without drying, as shown by two "dry" tested groups in Fig. 7. For example, the fracture toughness of the specimen without silane treatment measured in "dry" condition is $46 \%$ of the control group after conditioned in water for two months. This suggests that $24 \%$ of the fracture toughness of the interface can be recovered simply by drying the conditioned specimens in the laboratory for two days. This observation confirms that part of the lost interface strength induced by moisture is reversible, as revealed by Tuakta and Büyüköztürk [26]. According to Tuakta and Büyüköztürk, this reversible portion of the fracture toughness is due to the plasticization of the adhesive induced by moisture. It should be pointed out two-day drying in laboratory is not sufficiently to drive all absorbed water along the FRP-to-concrete interface. Therefore, the regained fracture toughness measured in dry condition shown in Fig. 7 is not the whole reversible portion of the fracture toughness of the interface. 
Table 5 Experimental results of the fracture toughness of FRP-to-concrete interfaces

\begin{tabular}{llllllllllllllll}
\hline & & \multicolumn{3}{c}{ wet-untreated } & \multicolumn{4}{c}{ wet-silane } & \multicolumn{4}{c}{ dry-untreated } & \multicolumn{4}{c}{ dry-silane } \\
\cline { 2 - 14 } $\begin{array}{l}\text { Time } \\
\text { (months) }\end{array}$ & Control & 1 & 3 & 6 & 1 & 3 & 6 & 1 & 3 & 6 & 1 & 3 & 6 \\
\hline Fracture & 1.013 & 0.448 & 0.224 & 0.245 & 0.477 & 0.226 & 0.347 & 0.390 & 0.524 & 0.510 & 0.680 & 0.600 & 0.491 \\
toughness & 1.174 & 0.306 & 0.293 & 0.259 & 0.583 & 0.318 & 0.314 & 0.700 & 0.605 & 0.479 & 0.770 & 0.677 & 0.528 \\
$(\mathrm{~N} / \mathrm{mm})$ & 1.183 & 0.418 & 0.192 & 0.205 & 0.628 & 0.385 & 0.229 & 0.576 & 0.400 & 0.580 & 0.640 & 0.634 & 0.604 \\
& 1.084 & - & - & - & - & - & - & - & - & - & - & - & - \\
\hline Average & 1.11 & 0.39 & 0.24 & 0.24 & 0.56 & 0.31 & 0.30 & 0.56 & 0.51 & 0.52 & 0.70 & 0.64 & 0.54 \\
\hline$\sigma_{\overline{\mathrm{x}}}$ & 0.081 & 0.075 & 0.052 & 0.028 & 0.078 & 0.080 & 0.061 & 0.156 & 0.103 & 0.052 & 0.067 & 0.038 & 0.057 \\
\hline
\end{tabular}

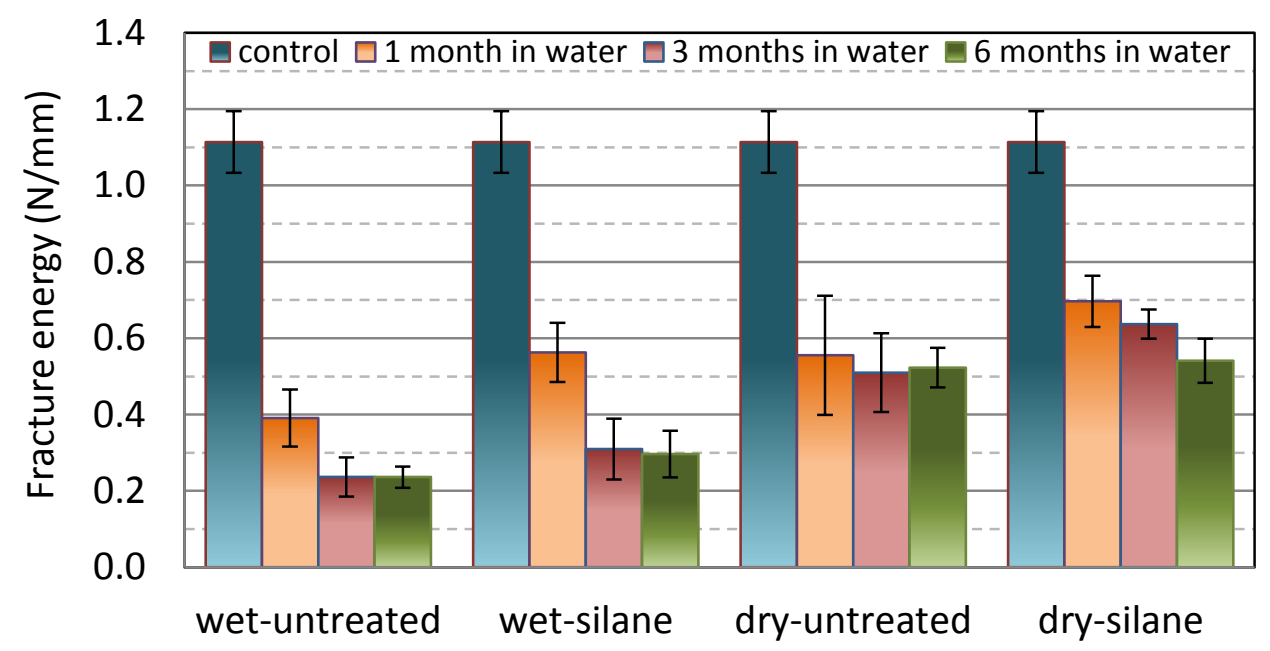

Fig. 7 Degradation of the FRP-to-concrete interfaces induced by submerging the specimen in water

Testing results of the FRP-to-concrete interface using specimens shown in Fig. 1(b) conditioned by submerging only the bottom half of the concrete blocks in water are presented in Table 6 and the average values with standard deviations are shown in Fig. 8. Similar to the case of full immersion conditioning, the fracture toughnesses of the FRP-to-concrete interfaces were significantly reduced by the half-immersion conditioning too. The steady residual fracture toughness is reached after eight-weeks conditioning. Without silane treatment, the residual fracture toughness of the interface (calculated as the average fracture toughness of the interface measured after 8 and 16 weeks conditioning) was reduced to $31 \%$ of that of the control one by 
the half immersion conditioning. With silane treatment, this residual fracture toughness was increased to $58 \%$ of that of the control one, confirming once again the effectiveness of silane treatment on enhancing the durability of the interface. Compared with the fully immersed specimens, the half-immersed specimens exhibit significantly higher residual fracture toughness, revealing that conditioning methods have significant effect on the durability testing result.

Table 6 Experimental results of the fracture toughness of FRP-to-concrete interfaces of the proposed specimen

\begin{tabular}{cccccccc}
\hline & & \multicolumn{3}{c}{ wet-untreated } & \multicolumn{3}{c}{ wet-silane } \\
\cline { 3 - 8 } $\begin{array}{c}\text { Time } \\
\text { (weeks) }\end{array}$ & Control & 4 & 8 & 16 & 4 & 8 & 16 \\
\hline Fracture & 1.33 & 0.44 & 0.47 & 0.52 & 1.03 & 0.91 & 0.77 \\
toughness & 1.06 & 0.56 & 0.38 & 0.41 & 0.66 & 0.62 & 0.63 \\
$(\mathrm{~N} / \mathrm{mm})$ & 1.17 & 0.46 & 0.26 & 0.29 & 0.62 & 0.74 & 0.76 \\
& 1.41 & - & - & & 0.50 & - & - \\
\hline Average & $\mathbf{1 . 2 4}$ & $\mathbf{0 . 4 9}$ & $\mathbf{0 . 3 7}$ & $\mathbf{0 . 4 0}$ & $\mathbf{0 . 7 0}$ & $\mathbf{0 . 7 6}$ & $\mathbf{0 . 7 2}$ \\
\hline$\sigma_{\bar{x}}$ & 0.156 & 0.066 & 0.107 & 0.115 & 0.227 & 0.149 & 0.078 \\
\hline
\end{tabular}

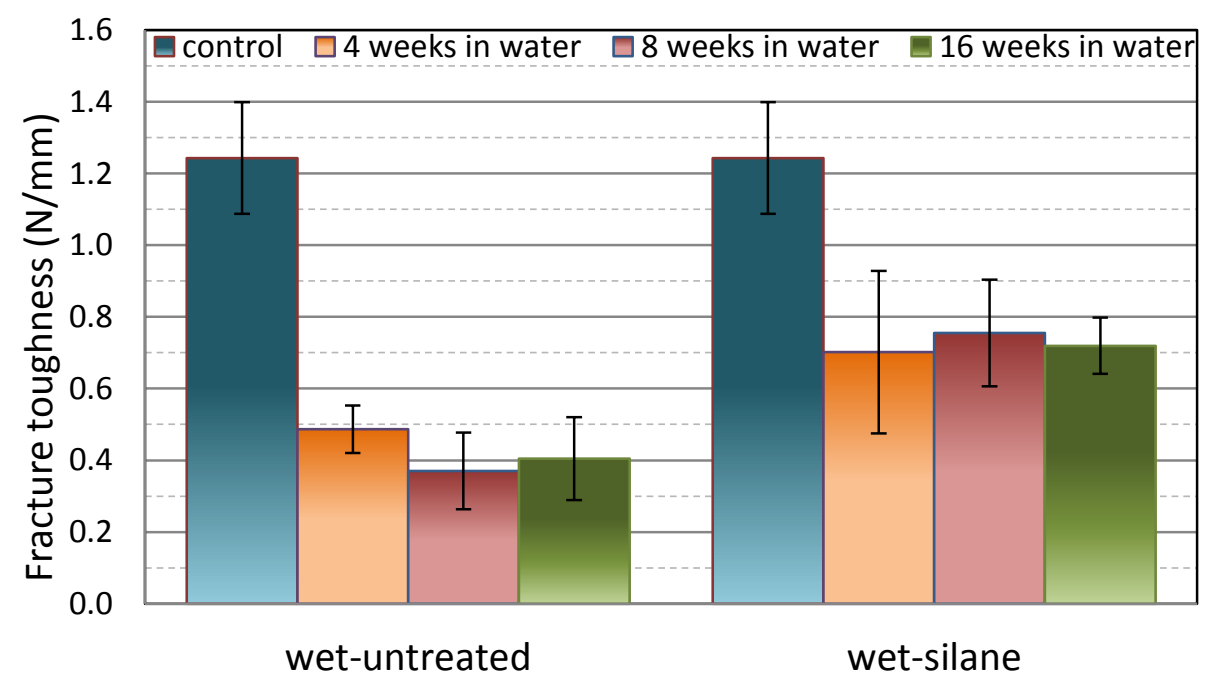

Fig. 8 Degradation of the CFPR-to-concrete interface induced by submerging the bottom half of the specimen in water.

The epoxy side of the debonded specimen conditioned by full immersion for three months are shown in Fig. 9. As shown in Fig. 9(a), the specimen without silane treatment has a very 
clean epoxy surface, suggesting that debonding is mainly through the epoxy-concrete interface. As comparison, a very thin layer of concrete can be observed on the epoxy layer of the specimen treated with silane shown in Fig. 9(b), indicating that debonding is cohesive through the adjacent concrete substrate in this specimen. This is not surprising since silane can create covalent bonds between the epoxy and the concrete, making it difficult for water molecules to displace the adhesive from the concrete surface. If the specimen without silane treatment were dried in laboratory for two days before testing, a mixed adhesive and cohesive debonding mode can be observed, as shown in Fig. 9(c). It can be seen that the inner part of the epoxy surface mostly shows the adhesive failure, while the outer bound of the interface exhibits the cohesive failure. This is due to the nature of the drying process in the specimen, in which more water can be evaporated in the exterior portions of the interface than in the inner part. As a result, more strength can be recovered in the outer bound of the interface than in the inner part, leading to mixed failure mode observed in Fig. 9(c).

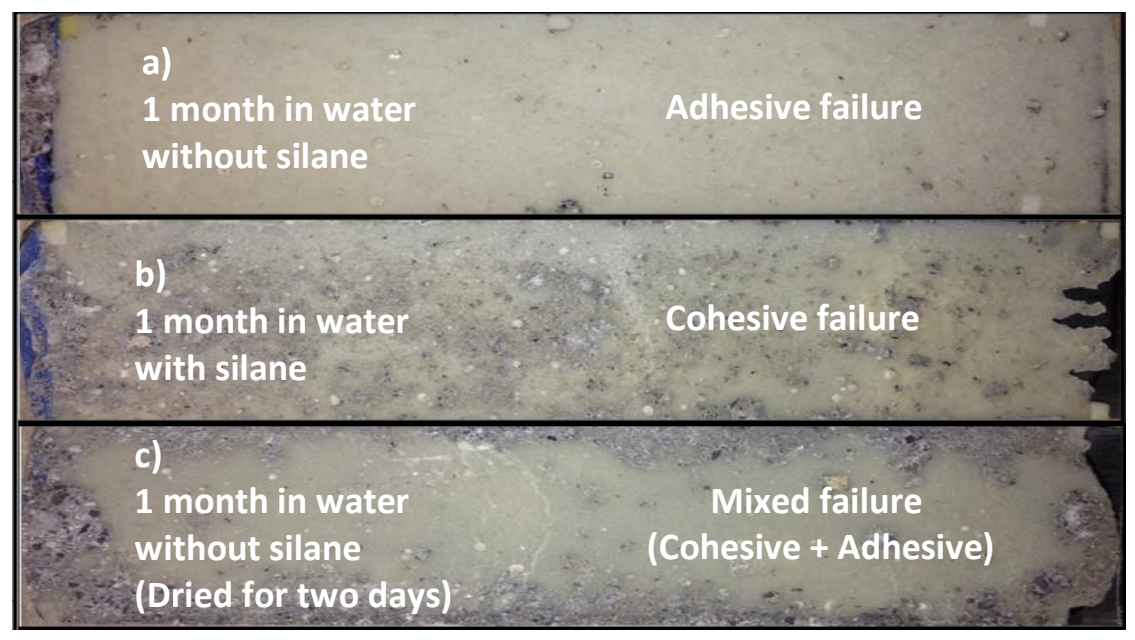

Fig. 9. Epoxy side of the debonded FRP-to-concrete interface specimens conditioned by full immersion

Debonding mode of the specimens conditioned by submerging the bottom half of the concrete block in water are demonstrated in Fig. 10. Figure 10(a) shows the epoxy side of the 
debonded specimen of the control group. A layer of concrete is attached to the epoxy side, suggesting a cohesive debonding mode for the control specimen. After four-week conditioning, the debonding mode changes to mixed mode (cohesive and adhesive) as indicated by a small amount of concrete particles scattered on the epoxy surface (Fig. 10(b)). More concrete residue can be found on the epoxy side of the specimen treated with silane as shown in Fig. 10(c), suggesting that more cohesive debonding is occurred in this specimen. This is not unexpected since silane coupling agent can enhance the resistance of the bonds between the epoxy and concrete to water attack. As a result, higher bond strength exists between the epoxy and the concrete than in the untreated specimen. If this strength is higher than that of the adjacent concrete, debonding will occur within the concrete, rather than along the interface, leading to more "cohesive failure mechanism" and higher fracture toughness of the debonding. After eight and sixteen weeks conditioning, less concrete particles were attached to the debonded untreated interfaces. Specimens treated with silane also shows the similar trend. Nevertheless, more concrete residue can be found on these specimens than on those without surface treatment, as shown in Fig. 10, indicating the effectiveness of silane coupling agent on enhancing the durability of the FRP-to-concrete interface.

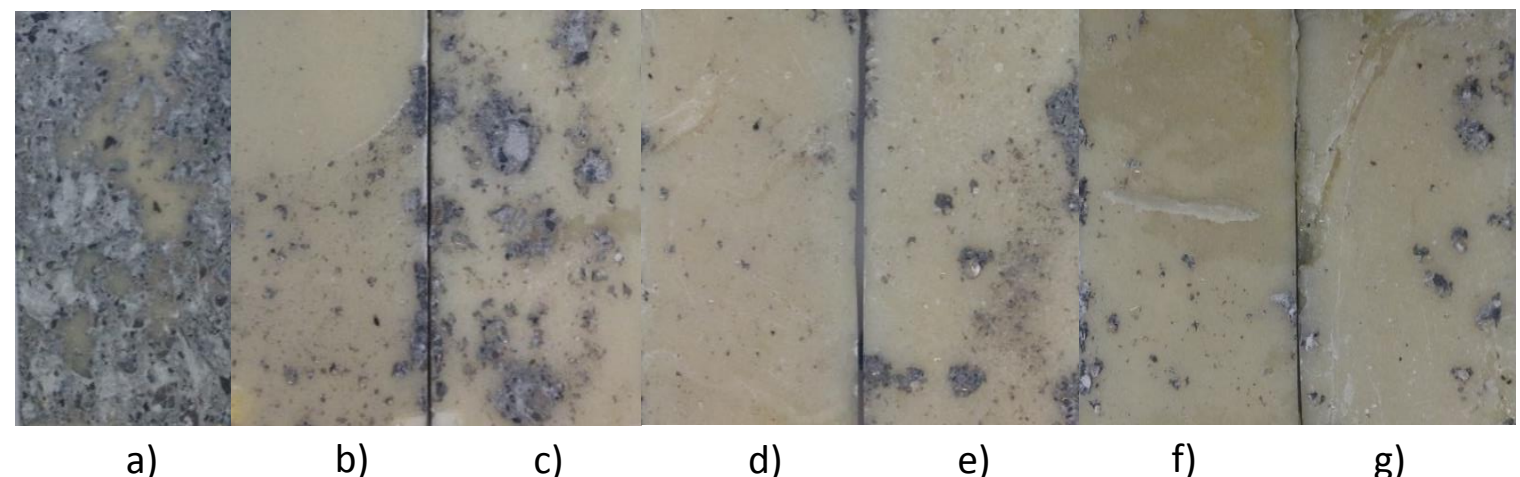

Fig. 10. Epoxy side of the debonded specimens conditioned through half immersion: a) control specimen; b) 4 weeks in water (untreated); c) 4 weeks in water (treated); d) 8 weeks in water 
(untreated); e) 8 weeks in water (treated); f) 16 weeks in water (untreated); g) 16 weeks in water (treated).

\subsection{Water absorption testing results}

Moisture diffusion testing results of CFRP, epoxy, and concrete substrate are shown in Fig. 11. In this figure, the gains of moisture content of the specimens are presented versus the square root of time per unit thickness. Numerical fitting based on Fickian's law as proposed before was used to determine the diffusivity of these materials. The resulting diffusion parameters of the materials are shown in Table 7 and used in the following diffusion simulation. As shown in Fig. 11(a), Fickian's law matches the testing data very well initially. After extended exposure in water $\left(30 \mathrm{hr}^{1 / 2} / \mathrm{mm}\right)$, however, the water absorbed by the CFRP starts to deviate from the Fickian's law, indicating a non-Fickian water absorbing process at this phase. Similar dual-phase water absorption behavior can be also observed on the epoxy, as shown in Fig. 11(b). This dualphase diffusion behavior of the epoxy was also observed in previous study [35] even though the authors may be unaware of it. Ouyang and Wan studied the moisture absorption behaviors at different relative humidities of the epoxy which they used to bond CFRP to concrete [35], as shown in Fig. 12. It can be seen that the Fickian's law can fit the testing data only at low relative humidity. At higher relative humidity (above 64\%), a non-Fickian diffusion phase can be clearly identified on the absorption curves, and this non-Fickian diffusion phase becomes more pronounced at higher relative humidity.

Two mechanisms are responsible for this dual-phase moisture absorption of the epoxy shown in Figs. 11 and 12 [37]. At the early stage of the absorption, water molecules absorbed into the epoxy mainly reside in free volumes of the polymer. These free water molecules can then transfer to bound ones at relatively slow rate because some energy barriers must be overcome. Since water molecules diffuse faster in free volumes of the epoxy at the beginning of the 
sorption, the early stage of the water absorption is much faster. After the epoxy reaches its saturation state, the first mechanism slows down, and the second mechanism dominates, resulting non-Fickian diffusion behavior that typically causes a slowly increase of moisture uptake with time, as revealed by Figs. 11 and 12. The bound water in polymer can cause significant swelling of the epoxy, introducing severe stress concentration along the epoxyconcrete interface, and therefore, reducing the strength of the interface.

a)

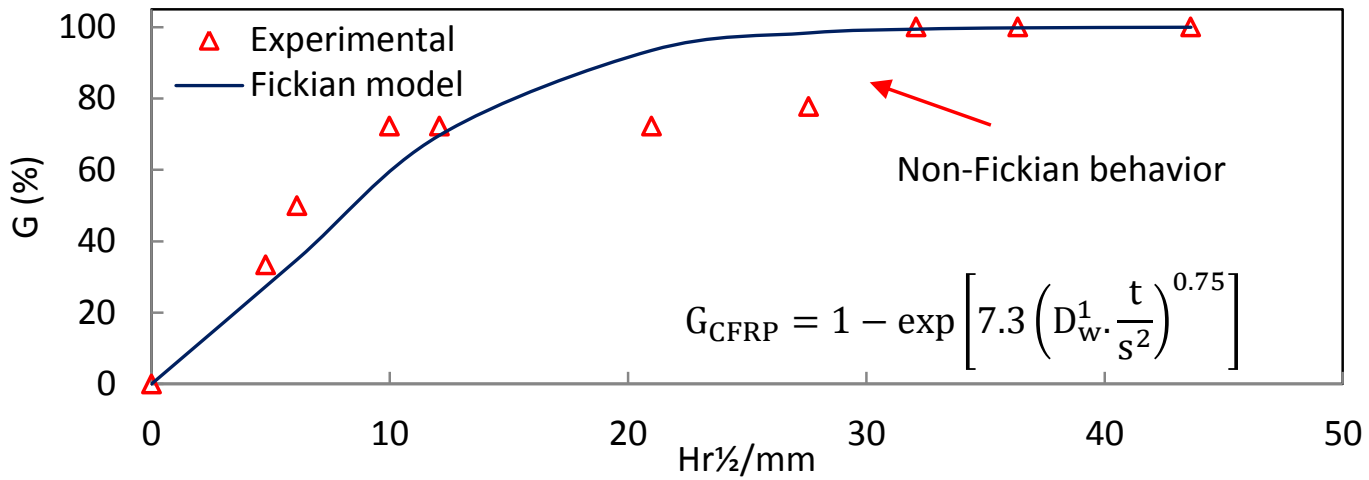

b)

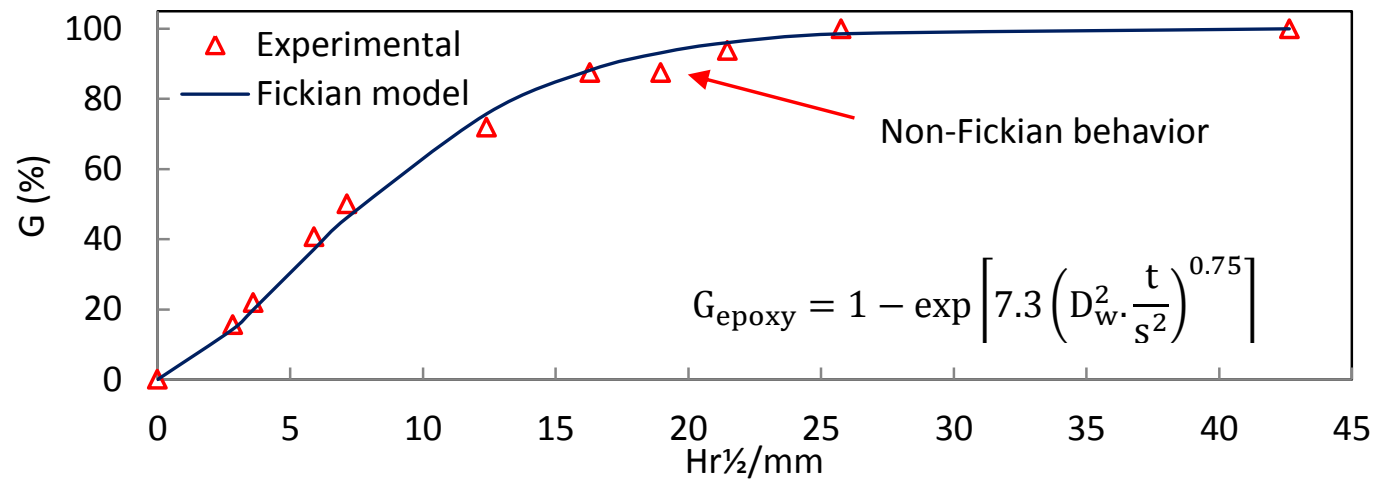

c)

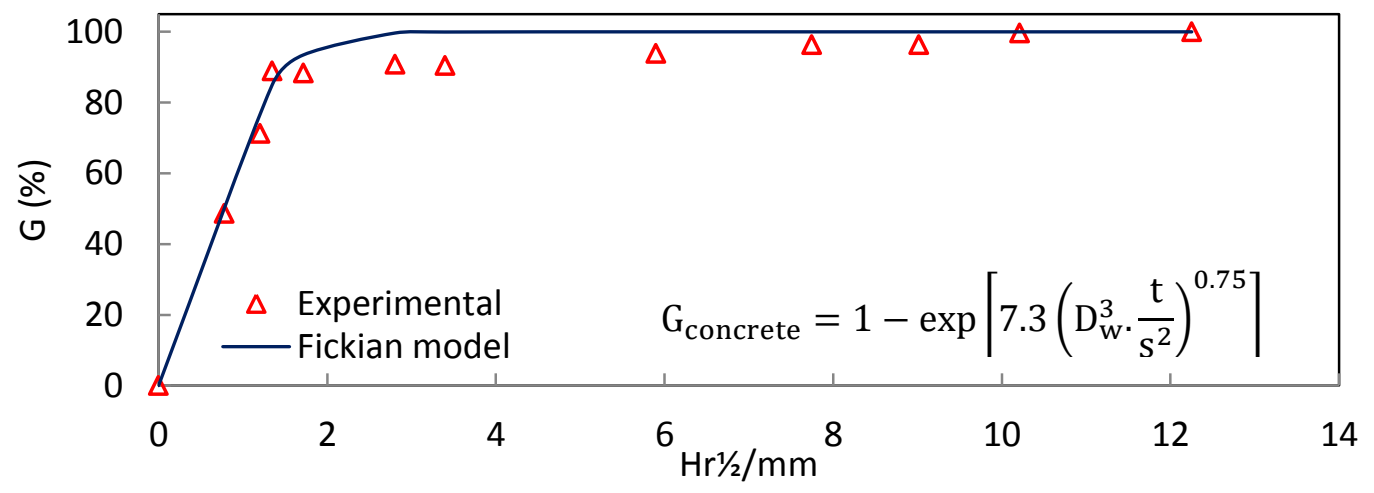


Fig. 11. Experimental and Fickian's absorption model for: a) CFRP; b) epoxy; c) concrete soaking in water at room temperature $\left(23^{\circ} \mathrm{C}\right)$.

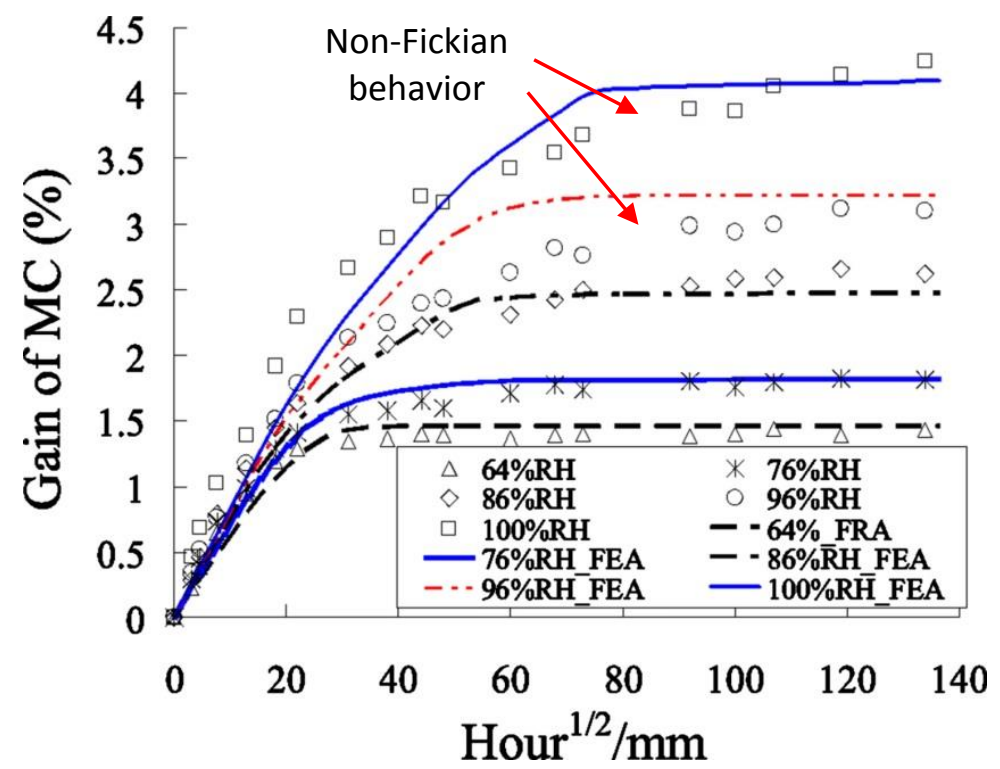

Fig. 12 Absorption behavior of the epoxy at different relative humidities [35].

Table 7 experimental diffusivities of materials used in fracture toughness tests

\begin{tabular}{llll}
\hline Material & CFRP & Epoxy & Concrete \\
\hline Diffusivity $\left(10^{-5} \mathrm{~mm}^{2} / \mathrm{sec}\right)$ & 0.0170 & 0.0203 & 2.54 \\
\hline
\end{tabular}

\subsection{Moisture diffusion simulation}

Figures 13 and 14 show the relative humidity contour of the fully immersed specimen evolving with immersion duration in the middle transverse section and the middle longitudinal section of the specimen, respectively. Since the diffusivity of the concrete is two orders of magnitude higher than that of the epoxy and the CFRP, water is mainly diffused into the specimen through the concrete block. The relative humidity at any spot of the specimen is mainly 
determined by its distance to the external water source. For this reason, moisture distribution along the epoxy-concrete interface is non-uniform in both the longitudinal and the transverse directions, as shown in Fig. 15.

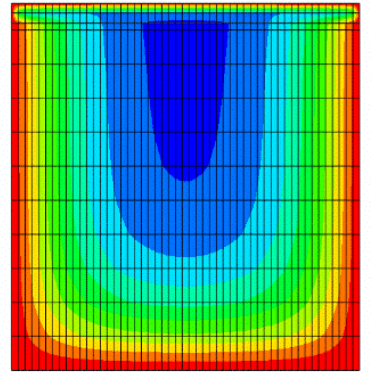

a)

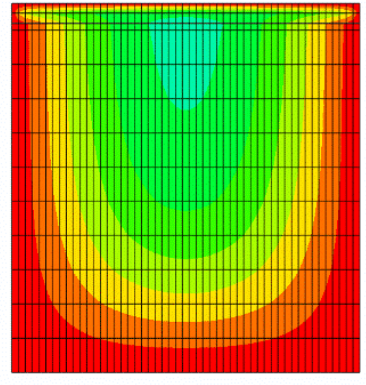

b)
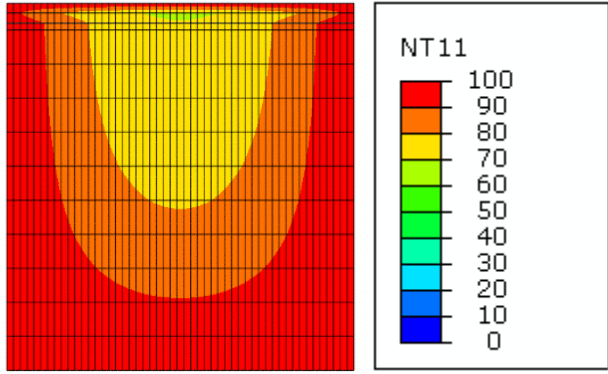

c)

Fig. 13 Relative humidity contour of the specimen evolving with immersion duration in the middle transverse section: a) 1 month; b) 3 months; c) 6 months.

a)

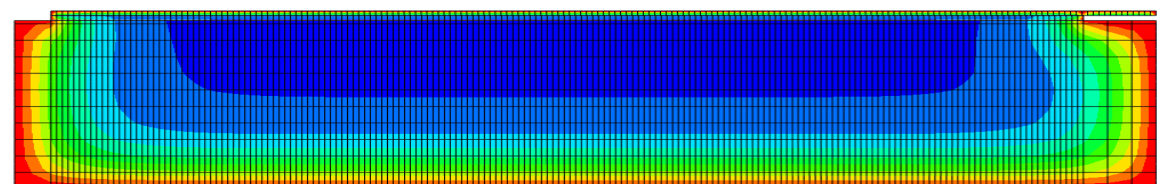

b)

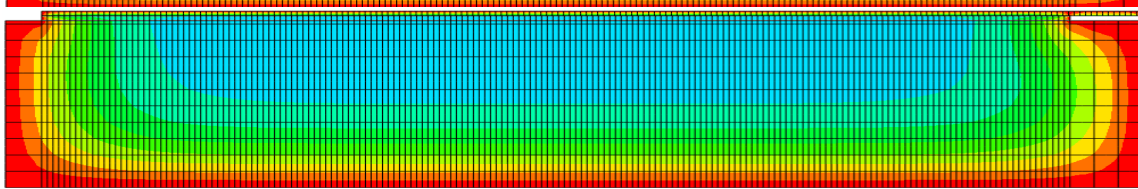

c)
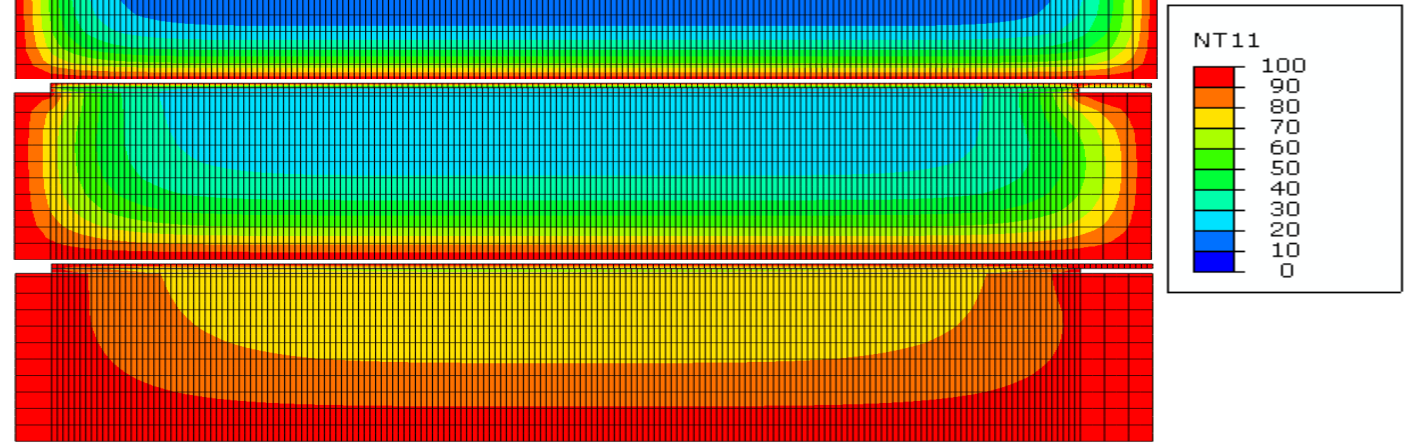

Fig.14 Relative humidity contour evolving with immersion duration in the middle longitudinal section: a) 1 month; b) 3 months; c) 6 months.

It is necessary to create a uniform relative humidity distribution along the interface so that the intrinsic relationship between the degradation of the interface and $\mathrm{I}_{\mathrm{RH}}$ can be established. Such a relationship is needed for reliable prediction of the durability of the interface. It can also shed new lights on the deterioration mechanisms of the interface under water attack. It is easy to overcome the non-uniform distribution of $\mathrm{I}_{\mathrm{RH}}$ along the longitudinal direction of the interface 
because it only affects a small zone within $30 \mathrm{~mm}$ from the edge of the epoxy, as shown in Fig. 15(b). Out of this zone, $\mathrm{I}_{\mathrm{RH}}$ in the longitudinal direction is almost a constant. Therefore, to avoid the effect of this non-uniform distribution zone on the fracture toughness measurement, we can first drive the crack tip into the uniform distribution zone, and then carry out the fracture toughness measurement. However, it is not easy to eliminate the non-uniform distribution of $\mathrm{I}_{\mathrm{RH}}$ across the interface as shown in Fig. 15(a). Existing studies [21,24-26] had to use an apparent relative humidity to replace the real $I_{R H}$. This apparent $\mathrm{I}_{\mathrm{RH}}$ was chosen as either the $\mathrm{I}_{\mathrm{RH}}$ at the middle section of the interface [21] or the average of the $I_{R H}$ across the interface. Clearly, the relationship between the interface fracture toughness and this apparent $\mathrm{I}_{\mathrm{RH}}$ of the interface does not reflect the intrinsic behavior of the interface subjected to moisture attack.

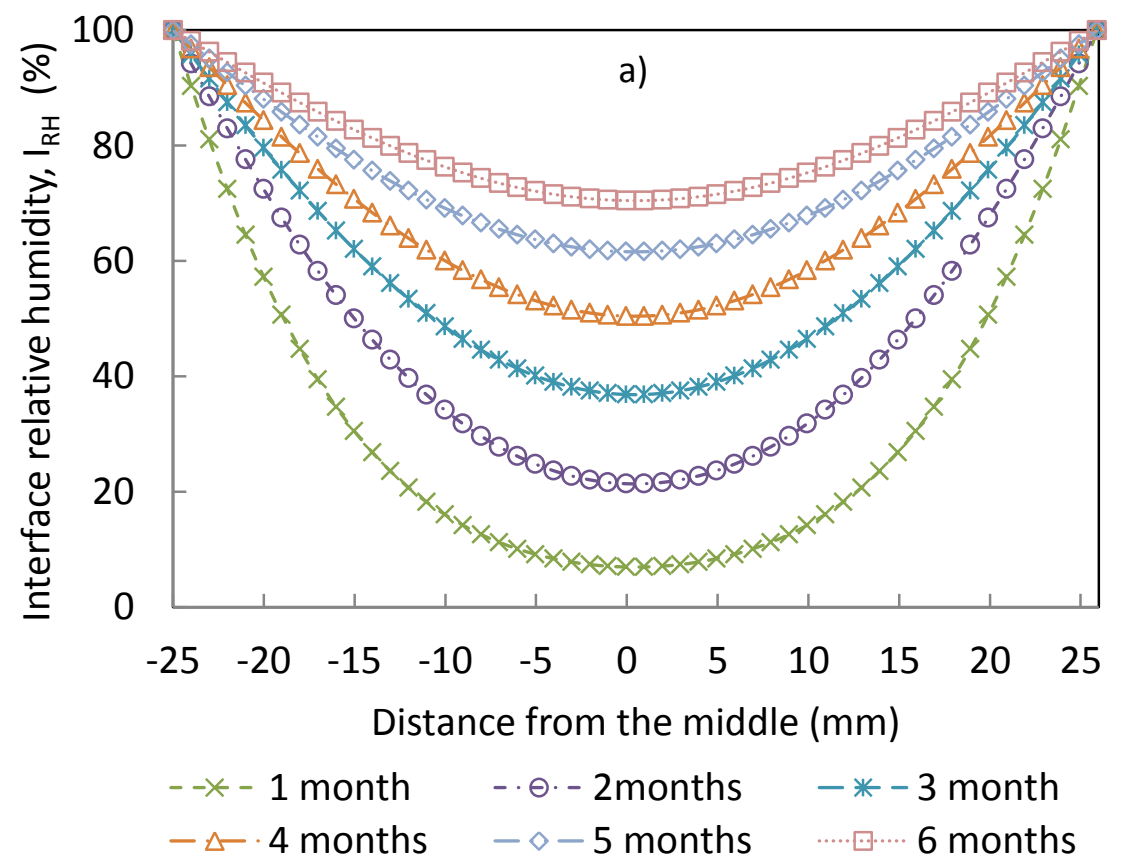




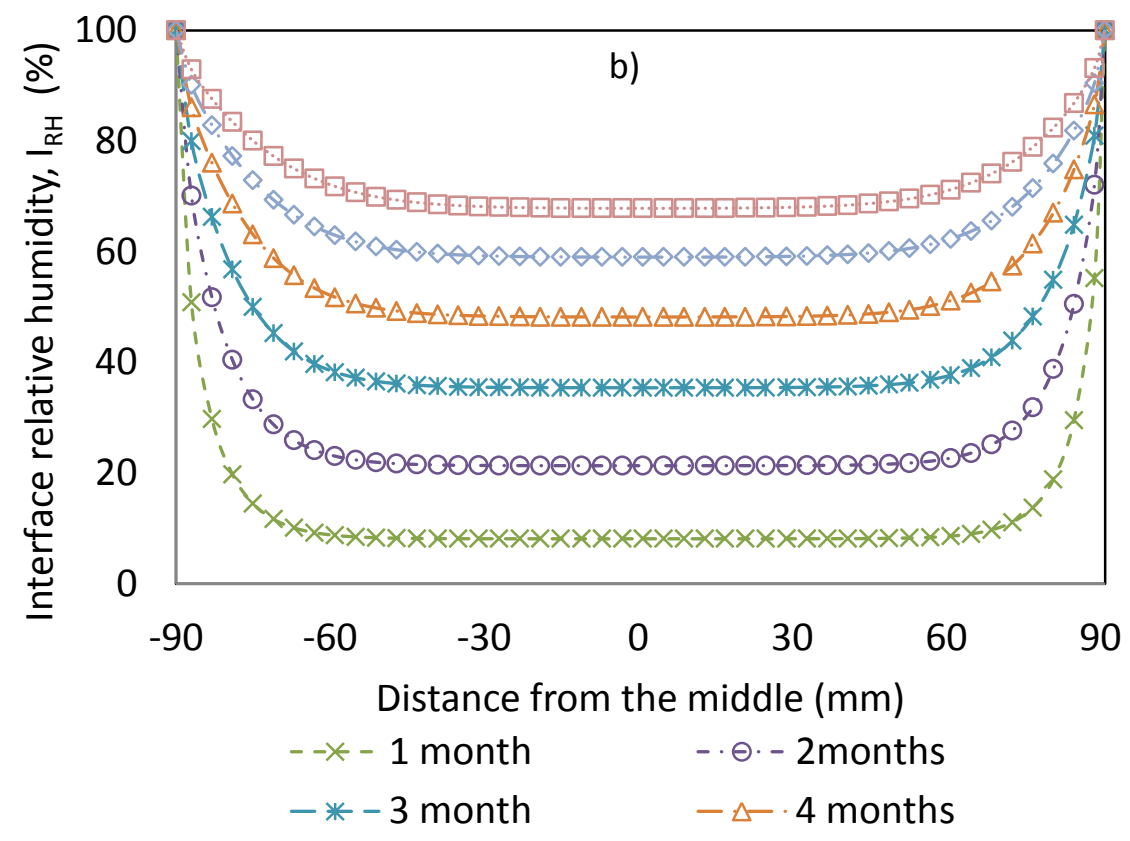

Fig. 15 Relative humidity distribution along the epoxy-concrete interface: a) In the middle transverse section; b) In the middle longitudinal section.

The relative humidity contour of a half immersed specimen is presented in Figs. 16 and 17. Compared with fully immersed specimens shown in Figs. 13 and 14, the relative humidity adjacent to and along the epoxy-concrete interface in these specimens is much lower because only the bottom half of the concrete block is immersed in water. Figures 18(a) and 18(b) show the $\mathrm{I}_{\mathrm{RH}}$ in the middle transverse and middle longitudinal sections, respectively. Although it is not possible to obtain perfect uniform $\mathrm{I}_{\mathrm{RH}}$ distribution across the epoxy-concrete interface, Fig. 18(a) shows half-immersion can create much more uniform $I_{R H}$ distribution across the interface. As a result, the apparent $I_{R H}$ chosen as the average of the $I_{R H}$ across the interface is closer to the real value than in the case of the full immersion. More intrinsic relationship between the degraded interface fracture toughness and $I_{R H}$ can be established by using this new conditioning method. 


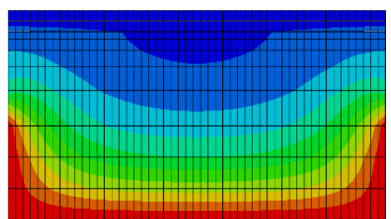

a)

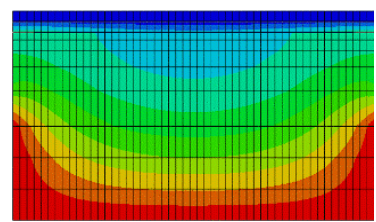

b)

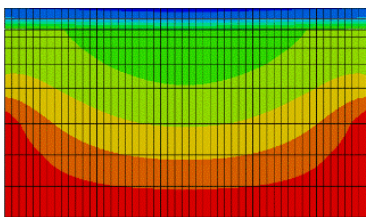

c)

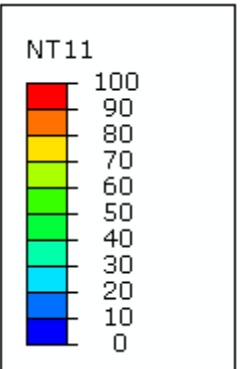

Fig. 16 Relative humidity contour of the half-immersed specimen evolving with immersion duration in the middle transverse section: a) 4 weeks; b) 8 weeks; c) 16 weeks.

a)

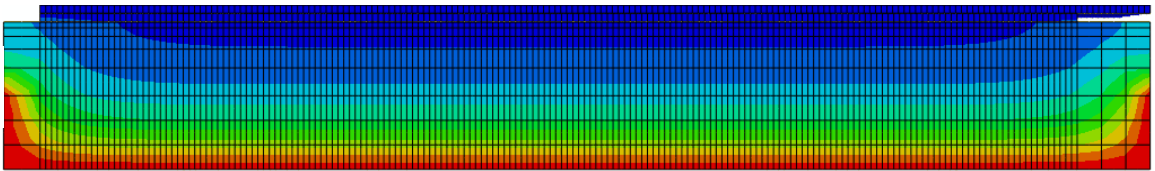

b)

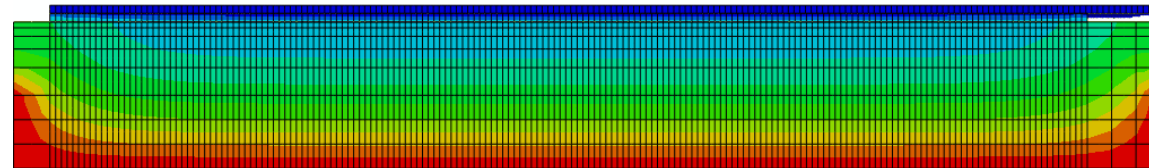

c)

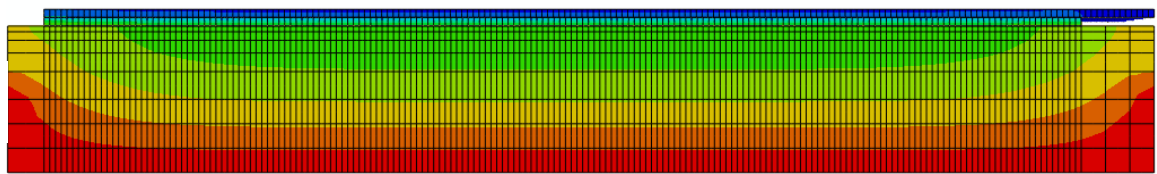

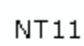

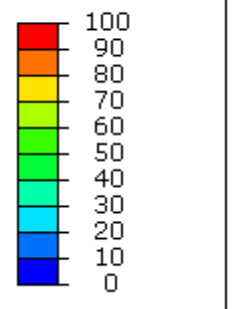

Fig. 17 Relative humidity contour of the half-immersed specimen evolving with immersion duration in the middle longitudinal section: a) 4 weeks; b) 8 weeks; c) 16 weeks.

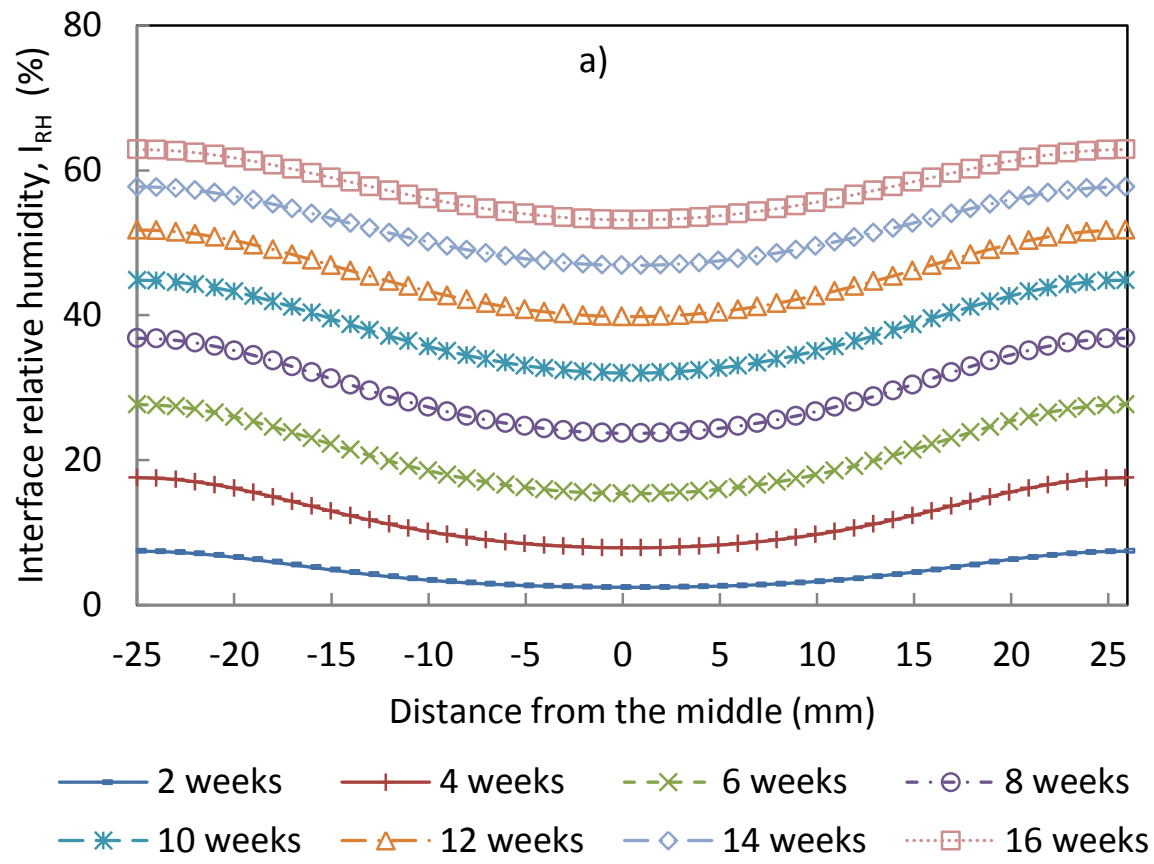




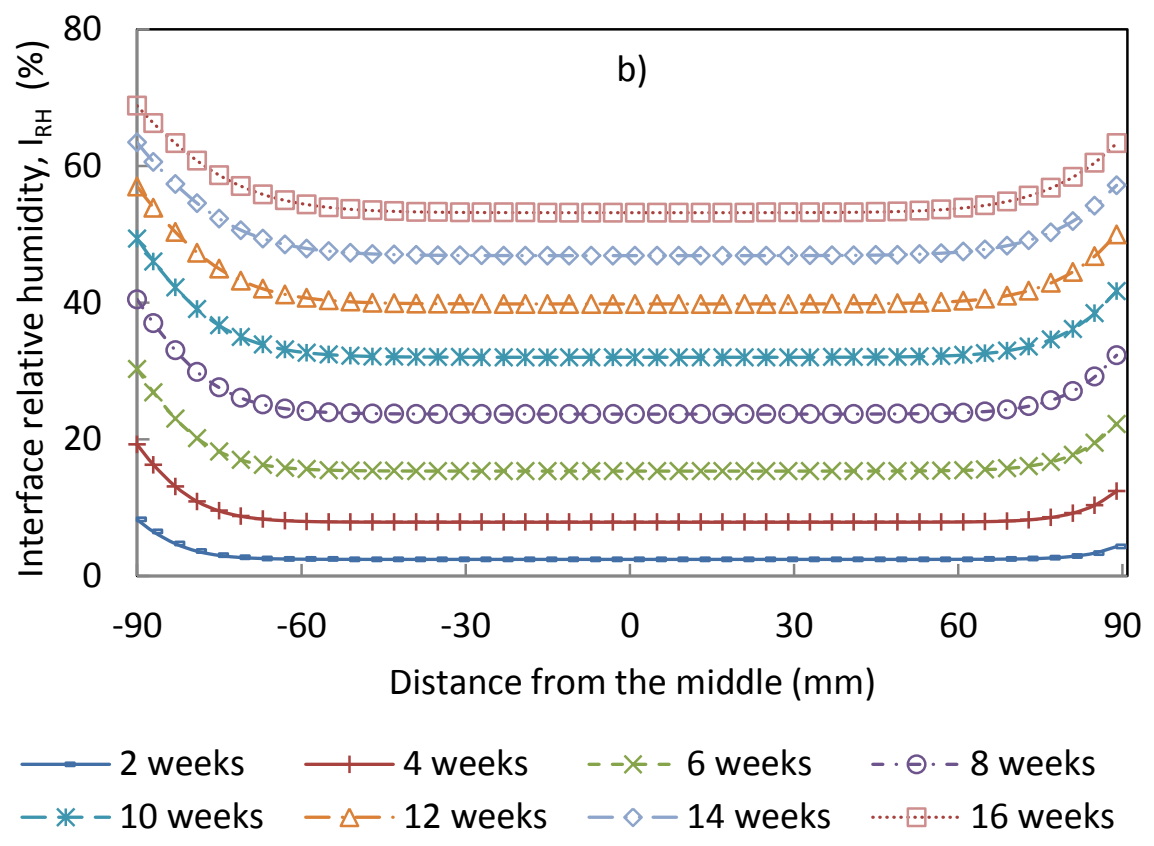

Fig. 18 Relative humidity distribution along the epoxy-concrete interface of the half immersed specimen: a) In the middle transverse section; b) In the middle longitudinal section.

\subsection{Relationship between the fracture toughness and $I_{R H}$}

The relationships between the fracture toughness and the apparent $I_{R H}$ obtained by fullimmersion (referred to as extrinsic in Fig. 19) and half immersion (referred to as intrinsic in Fig. 19) are shown in Fig. 19. It shows that the fracture toughness of the interface reduced with $I_{R H}$ and that silane treatment can enhance the fracture toughness of the interface, as anticipated. These relationships can be approximated by an exponential regression model as $G_{I}=\alpha \cdot e^{\left(-\beta . I_{R H}\right)}$,

where $\alpha$ and $\beta$ are constants and can be determined by fitting the experimental data to Eq. (7).

Table 8 shows the fitting values of these parameters for each test. Fitted curves for both untreated and treated interface are also presented in Fig. 19. Both curves can provide acceptable prediction of the fracture toughness of the interface reducing with apparent $I_{R H}$, especially at low $I_{R H}$. 


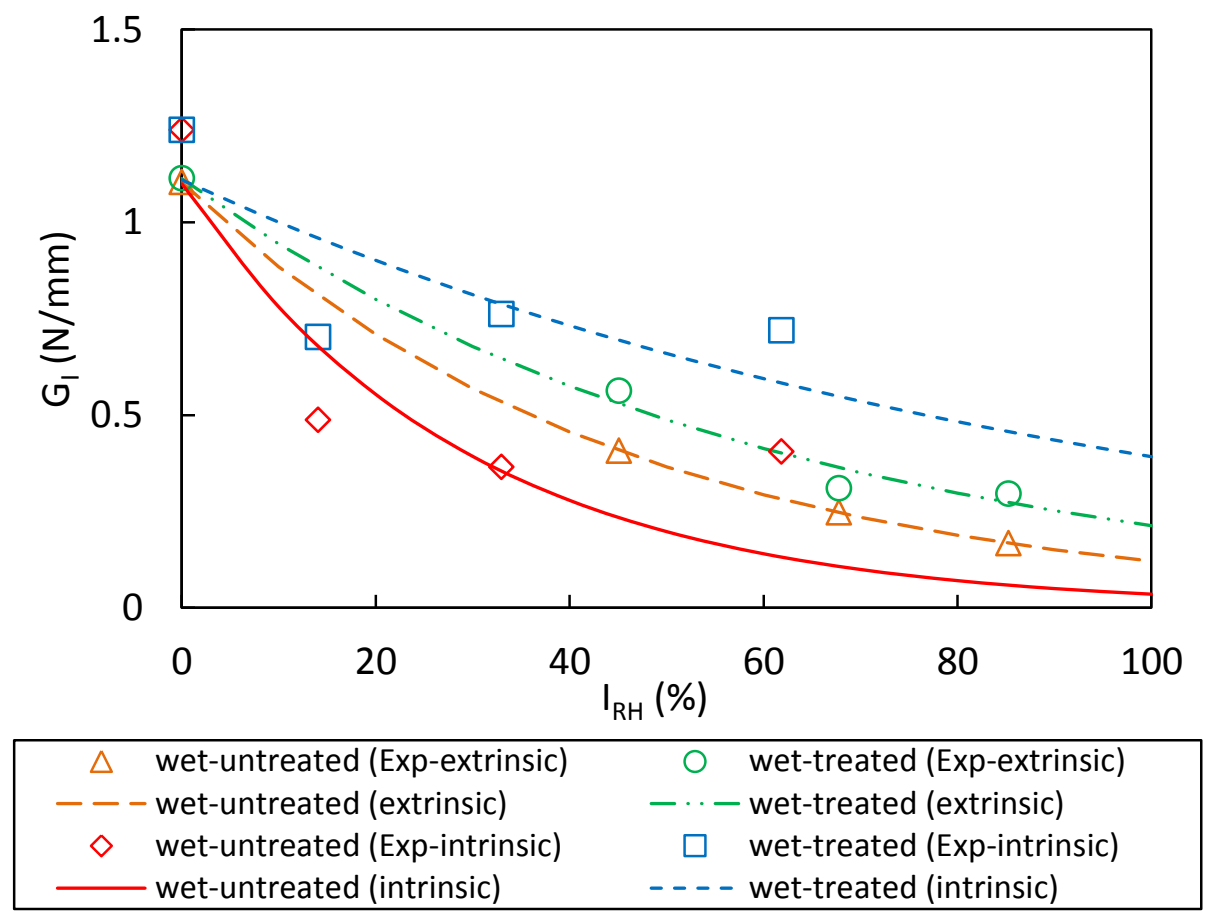

Fig. 19. Relationships between the fracture toughness and $I_{R H}$ obtained through full immersion and half-immersion.

Table 8 Parameters of the relationship between the fracture energy and the $I_{R H}$.

\begin{tabular}{lllll}
\hline & \multicolumn{2}{l}{ Intrinsic Fracture } & \multicolumn{2}{l}{ Extrinsic Fracture } \\
\cline { 2 - 5 } Parameters & untreated & treated & untreated & treated \\
\hline$\alpha$ & 1.10 & 1.11 & 1.10 & 1.11 \\
$\beta$ & 3.43 & 1.04 & 2.21 & 1.65 \\
\hline
\end{tabular}

Figure 19 shows that at the same apparent $I_{R H}$, the fracture toughness of the interface conditioned by full immersion is significantly lower than that conditioned through halfimmersion.

This discrepancy clearly shows that conditioning method can have significant effect on the durability testing result of the FRP-to-concrete interface subject to water attack. A few reasons can be responsible for this difference. 
The first and most obvious reason is the different distribution of $I_{R H}$ induced by these two different conditioning methods. Due to the difference in specimen's geometry and water levels, the distributions of $I_{R H}$ in fully immersed samples can be significantly different from those in half immersed samples, even though their apparent $\mathrm{I}_{\mathrm{RH}} \mathrm{S}$ are the same, as shown in Figs. 15 and 18.

The second possible reason is that water diffusion through the epoxy-concrete interface is ignored in calculating $\mathrm{I}_{\mathrm{RH}}$ for the fully immersed specimens. Under full immersion, water can diffuse through the epoxy-concrete interface. Due to the presence of micro-cracks and manufacturing defects along this interface, water diffusion along the epoxy-concrete interface can be much higher than through the bulky materials due to the effect of 'capillary diffusion', or seepage of the water near the interface [38]. Unfortunately, no practical method is available to measure this elevated diffusion of water along the epoxy-concrete interface. For this reason, water diffusion along the epoxy-concrete interface is ignored in the simulation in this study, as well as many existing studies $[26,35]$. As a result, the predicted $I_{R H}$ based on the FEA simulation shown in Fig. 15 underestimates the $I_{R H}$ for the fully-immersed specimens.

The third possible reason is the swelling of the epoxy after conditioning through full immersion in water. Our previous study [15] has shown that significant swelling of the epoxy can be induced by water absorption, which can introduce localized stresses along the epoxyconcrete interface. Swelling of the epoxy can also be observed from the water absorption test shown in Figs. 11 and 12, both showing water absorption of the epoxy exhibits dual-phase behavior. The presence of the second phase usually indicates volumetric swelling and void enlarge in polymer [37]. Previous study [35] shows that water absorption of polymer follows a linear law (Henry's law) at low relative humidity, and then deviates from linearity positively as 
shown in Fig. 20. Generally, the swelling of the polymer is in proportion to the moisture content. Figure 20 suggests that the swelling of epoxy at high relative humidity can be significantly higher than at low relative humidity. In the case of half immersed specimens, it takes much longer time for the epoxy to reach the non-Fickian phase, as indicated by Figs. 11, 12. Its total water uptake is also significantly lower than that in a fully immersed specimen according to Fig. 20. As a result, the resulting hygroscopic swelling stress along the epoxy-concrete interface in the half immersed specimen is much lower than that in the fully immersed specimen, leading to higher residual fracture toughness as shown in Fig. 19.

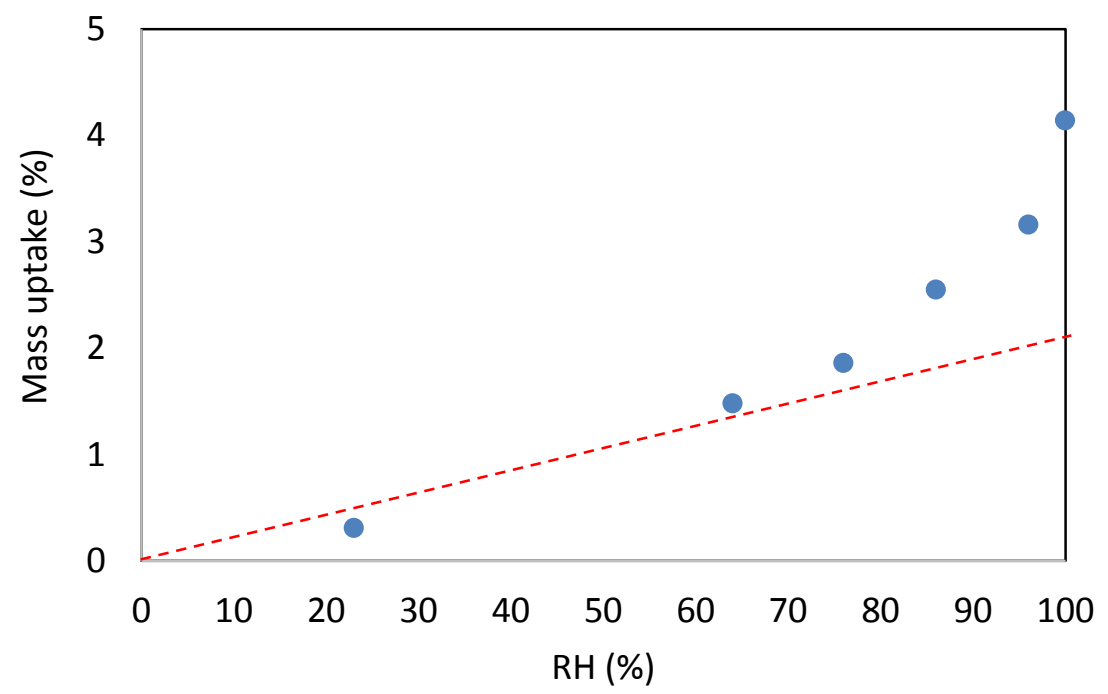

Fig. 20. Water absorption isotherm of the epoxy showing deviation from the Henry's law [35]

\section{Conclusions and Discussions}

This study examined the effects of conditioning methods and silane treatment on the residual fracture toughness of the FRP-to-concrete interface subject to water attack using a wedge driving test. The significant role of conditioning methods on the residual fracture toughness has been revealed, suggesting that the fracture toughness of the interface specimen conditioned through half immersion is much higher than that of the specimens conditioned through full immersion. 
Three possible reasons responsible for this difference have been proposed: 1) different moisture distributions are introduced by different conditioning methods; 2) diffusion along the epoxyconcrete interface in the fully immersed specimens is ignored; and 3) higher hydroscopic swelling stress along the epoxy-concrete interface is introduced by fully immersing specimens in water.

To fully understand the mechanism and accurately quantitate the deterioration induced by moisture to the FRP-to-concrete interface, the intrinsic relationship between the $I_{R H}$ and the fracture toughness of the interface should be obtained. To this end, a uniform distribution of the relative humidity should be created along the interface. This cannot be done by using the existing full-immersion conditioning method. The half-immersion conditioning method proposed in this study can produce more uniform distribution of the relative humidity along the interface. Although perfect uniform distribution of the relative humidity along the interface cannot be reached by the proposed new conditioning method, it at least provides a new direction to perfect the specimen design and conditioning method to create more uniform moisture distribution along the interface.

This study also confirms that using silane coupling agent can improve the residual fracture toughness of the interface subjected to water attack. A study on the mode-I failure mode showed that while the interface debonding for specimens conditioned in water is adhesive, applying silane coupling argent changes this adhesive failure to the cohesive one (i.e. within the concrete substrate). Since only one application condition was attempted in this study, further study is needed to find the optimal application conditions of silane so that the full potential of silane treatment on enhancing the durability of the FRP-to-concrete interface can be reached. 


\section{Acknowledgements}

This work was supported by the National Science Foundation under grant CMMI - 0927938 .

Any Opinions, findings and conclusions or recommendations expressed in this material are those of the author(s) and do not necessarily reflect those of the National Science Foundation.

\section{References}

[1] Herrmann AW. ASCE 2013 Report Card for America's Infrastructure. IABSE Symp. Rep., vol. 99, International Association for Bridge and Structural Engineering; 2013, p. 910 .

[2] Karbhari VM, Seible F, Hegemier GA. On the Use of Fiber Reinforced Composites for Infrastructure Renewal-A Systems Approach. Mater. New Millenn., ASCE; 1996, p. 1091-100.

[3] Sharif A, Al-Sulaimani GJ, Basunbul IA, Baluch MH, Ghaleb BN. Strengthening of initially loaded reinforced concrete beams using FRP plates. ACI Struct J 1994;91.

[4] Täljsten B. Defining anchor lengths of steel and CFRP plates bonded to concrete. Int J Adhes Adhes 1997;17:319-27.

[5] Lorenzis L De, Nanni A. Characterization of FRP rods as near-surface mounted reinforcement. J Compos Constr 2001;5:114-21.

[6] Seible F, Priestley MJN, Hegemier GA, Innamorato D. Seismic retrofit of RC columns with continuous carbon fiber jackets. J Compos Constr 1997;1:52-62.

[7] Bakis CE, Ganjehlou A, Kachlakev DI, Schupack M, Balaguru PN, Gee DJ, et al. Guide for the design and construction of externally bonded FRP systems for strengthening concrete structures. Rep by ACI Comm 2002;440.

[8] Porter ML, Harries K. Future directions for research in FRP composites in concrete construction. J Compos Constr 2007;11:252-7.

[9] Karbhari VM, Chin Jw, Hunston D, Benmokrane B, Juska T, Morgan R, et al. Durability gap analysis for fiber-reinforced polymer composites in civil infrastructure. J Compos Constr 2003;7:238-47.

[10] Teng JG, Smith ST, Yao J, Chen JF. Intermediate crack-induced debonding in RC beams and slabs. Constr Build Mater 2003;17:447-62.

[11] Al-Dulaijan SU, Al-Zahrani MM, Nanni A, Boothby TE. Effect of environmental preconditioning on bond of FRP reinforcement to concrete. J Reinf Plast Compos 2001;20:881-900.

[12] Davalos JF, Kodkani SS, Ray I, Lin C. Fracture evaluation of GFRP — concrete interfaces for freeze - thaw and wet-dry cycling. J Compos Mater 2008;42:1439-66.

[13] Subramaniam K V, Ali-Ahmad M, Ghosn M. Freeze-thaw degradation of FRP-concrete interface: impact on cohesive fracture response. Eng Fract Mech 2008;75:3924-40. 
[14] Mukhopadhyaya P, Swamy RN, Lynsdale CJ. Influence of aggressive exposure conditions on the behaviour of adhesive bonded concrete-GFRP joints. Constr Build Mater 1998;12:427-46.

[15] Amidi S, Wang J. Subcritical debonding of FRP-to-concrete bonded interface under synergistic effect of load, moisture, and temperature. Mech Mater 2016;92:80-93.

[16] Baldan A. Adhesively-bonded joints in metallic alloys, polymers and composite materials: Mechanical and environmental durability performance. J Mater Sci 2004;39:4729-97.

[17] Au C, Büyüköztürk O. Peel and shear fracture characterization of debonding in FRP plated concrete affected by moisture. J Compos Constr 2006;10:35-47.

[18] Büyüköztürk O, Yu T-Y. Understanding and assessment of debonding failures in FRPconcrete systems. 17th Int. Congr. Adv. Civ. Eng. Yildiz Tech. Univ. Istanbul, Turkey, 2006.

[19] Lyons J, Laub D, Giurgiutiu V, Petrou M, Salem H. Effect of hygrothermal aging on the fracture of composite overlays on concrete. J Reinf Plast Compos 2002;21:293-309.

[20] Karbhari VM, Engineer M. Effect of environmental exposure on the external strengthening of concrete with composites-short term bond durability. J Reinf Plast Compos 1996;15:1194-216.

[21] Ouyang Z, Wan B. Experimental and Numerical Study of Moisture Effects on the Bond Fracture $\quad$ Energy of FRP/Concrete Joints. J Reinf Plast Compos 2007. doi: $10.1177 / 0731684407082952$.

[22] Wan B. The Effect of the Presence of Water on the Durability of Bond between CFRP and Concrete. J Reinf Plast Compos 2006;25:875-90. doi:10.1177/0731684406065140.

[23] He M-Y, Hutchinson JW. Kinking of a crack out of an interface. J Appl Mech 1989;56:270-8.

[24] Lau D, Büyüköztürk O. Fracture characterization of concrete/epoxy interface affected by moisture. Mech Mater 2010;42:1031-42.

[25] Büyüköztürk O, Lau D, Tuakta C. Durability and long-term performance modeling of frpconcrete systems. 6th Int. Conf. FRP Compos. Civ. Eng., 2012.

[26] Tuakta C, Büyüköztürk O. Conceptual model for prediction of FRP-concrete bond strength under moisture cycles. J Compos Constr 2011;15:743-56.

[27] Grace NF, Grace M. Effect of repeated loading and long term humidity exposure on flexural response of CFRP strengthened concrete beams. Proc. Int. Symp. Bond. Behav. FRP Struct. (BBFS 2005), Chen Teng, 2005, p. 539-46.

[28] Au C, Büyüköztürk O. Debonding of FRP plated concrete: a tri-layer fracture treatment. Eng Fract Mech 2006;73:348-65.

[29] Berry DH, Namkanisorn A. Fracture toughness of a silane coupled polymer-metal interface: Silane concentration effects. J Adhes 2005;81:347-70.

[30] Ye L, Friedrich K, Weimer C, Mai Y-W. Surface treatments and adhesion bonding between concrete and a CFRP composite. Adv Compos Mater 1998;7:47-61.

[31] Abel M-L, Allington RD, Digby RP, Porritt N, Shaw SJ, Watts JF. Understanding the 
relationship between silane application conditions, bond durability and locus of failure. Int J Adhes Adhes 2006;26:2-15.

[32] ASTM C33/C33M, Standard Specification for Concrete Aggregates 2013. doi:10.1520/C0033-03R06.

[33] ASTM C 192/C192M, Standard Practice for Making and Curing Concrete Test Specimens in the Laboratory 2014. doi:10.1520/C0192_C0192M.

[34] Zhang C. Mechanics and subcritical cracking of FRP-concrete interface 2011.

[35] Ouyang Z, Wan B. Modeling of moisture diffusion in FRP strengthened concrete specimens. J Compos Constr 2008;12:425-34.

[36] Shen C-H, Springer GS. Moisture absorption and desorption of composite materials. J Compos Mater 1976;10:2-20.

[37] Shirangi MH. Simulation-based Investigation of interface delamination in plastic IC packages under temperature and moisture loading. Cuvillier; 2010.

[38] Zanni-Deffarges MP, Shanahan MER. Diffusion of water into an epoxy adhesive: comparison between bulk behaviour and adhesive joints. Int J Adhes Adhes 1995;15:13742. 